\title{
ICONOGRAPHIE RELIGIEUSE ET CONSCIENCE CIVIQUE AUX DERNIERS SIÈCLES DU MOYEN ÂGE: L'EXEMPLE DE SIENNE.
}

\author{
JEAN-PIERRE CAILLET
}

UDC 7.046(450)

7.033.5(450)

Original scientific paper

Manuscript received: 15. 12. 1995.

Revised manuscript accepted: 01. 04. 1996.
J.-P. Caillet

Université Paris X

Nanterre

France

On s'attache ici à présenter, dans le cadre d'une cité-état où le nombre des réalisations monumentales et mobilières permet d'en juger au mieux, l'infléchissement des programmes chrétiens par un courant dominant de la mentalité des nouvelles élites lä̈ques. L'entremise des saints locaux - et des saints contemporains, de plus en plus - y joue un rôle essentiel. Au-delà de l'analyse oeuvre par oeuvre, l'étude vise à dégager la complémentarité des composantes: par leur déploiement aux pôles majeurs (cathédrale, palais communal et place publique), ces programmes imposent en effet la notion d'une véritable osmose entre le sacré - où la figure mariale tient la première place - et l'autorité civile.

La "religion civique" apparaît bien aujourd'hui commel'une des expressions les plus caractéristiques de la foi chrétienne aux derniers siècles du Moyen âge: l'historien G. Lobrichon l'a excellemment souligné dans son récent ouvrage de synthèse sur la piété des laïcs: il y observe en effet qu'à côté du mouvement de réaffirmation de l'unité de l'Etat dans le corps du monarque (religion "royale", suivant ses propres termes), le culte rendu par la cité à son (ses) saint(s) patron(s) traduisait alors un désir pressant d'affirmation d'identité et de légitimation par le sacré1. Un important colloque organisé à l'Université de Paris-X, et consacré à ce même thème, vient aussi opportunément d'en faire ressortir l'intérêt à travers plusieurs de ses aspects politiques, sociaux, culturels et artistiques² ${ }^{2}$ C'est précisément un ensemble de réalisations picturales et plastiques, dans le cadre de la ville de Sienne et de la seconde moitié du XIIIè s. à la fin du XVè s., que nous prendrons ici en compte pour illustrer le phénomène. L'approfondissement de ce cas se recommande d'autant que les oeuvres en question, assez nombreuses et bien documentées, pour la plupart encore in situ, développent des iconographies presque idéalement complémentaires; leur distribution topographique - dans les deux pôles religieux et civil — et chronologique - sans hiatus sur une durée de plus de deux siècles assure leur incontestable représentativité tout en permettant de reconnaître la progressive amplification de certaines tendances.

Le point de départ de l'enquête pourrait être constitué par le retable mis en place à l'autel majeur de la cathédrale entre la mémorable victoire remportée par les Siennois sur les Florentins à Montaperti (septembre 1260) et la dédicace du sanctuaire rebâti $(1267)^{3}$. De ce retable, attribué à l'un des artistes communément réunis sous le nom de Guido da Siena, ne subsiste que la partie centrale, avec le buste d'une Vierge à l'Enfant du type de l'Hodegetria byzantine. Mais les restes de l'arc trilobé surmontant le visage de Marie, ainsi que le montage au moyen de planches disposées horizontalement, permettent de restituer un panneau relativement large ${ }^{4}$. H. Belting a suggéré que l'on y avait associé à la Vierge les quatre saints patrons de Sienne: leur présence quelques décennies plus tard à la verrière du choeur comme sur le retable de Duccio - nous y reviendrons ci-après - lui a semblé à cet égard un argument suffisant ${ }^{5}$. L'hypothèse s'avère assurément séduisante. Il faut rappeler, à ce sujet, que le jour précédant la bataille de Montaperti avait donné lieu, dans la cathédrale même, à une pathétique manifestation de foi des citoyens de Sienne: c'est alors que, dans l'imminence de l'affrontement avec l'ennemi, la ville s'était solennellement vouée à Marie; et puisque les patrons locaux en question - à l'époque, Crescentius, Savinus, Ansanus et l'apôtre Barthélemy avaient leurs propres autels dans la crypte ${ }^{6}$, il ne serait guère surprenant que ces intercesseurs les plus naturels aient été associés dès que possible à la dévotion accrue dont devenait l'objet la dispensatrice de victoire. On ne saurait, cependant, avoir en cela de certitude: le voeu de septembre 1260 avait d'ailleurs été prononcé devant l'ancien retable, originellement antependium, dont la partie centrale seule subsistante montre une Vierge à l'Enfant trônante (la Madonna degli occhi grossi)

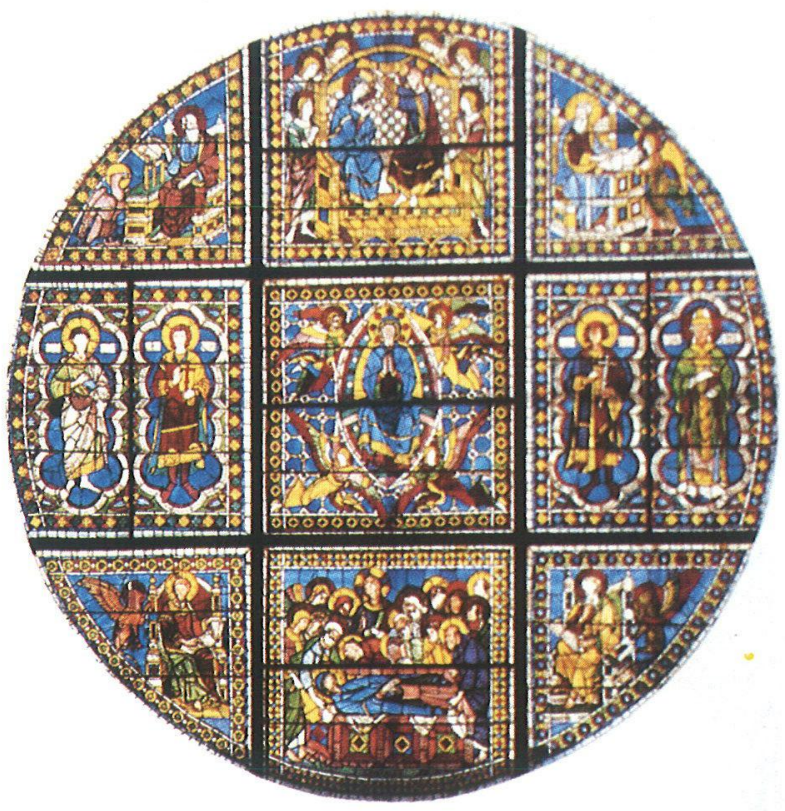

Fig. 1. Cathédrale, vitrail du fond du chevet (par Cimabue ou Duccio, 1287). 


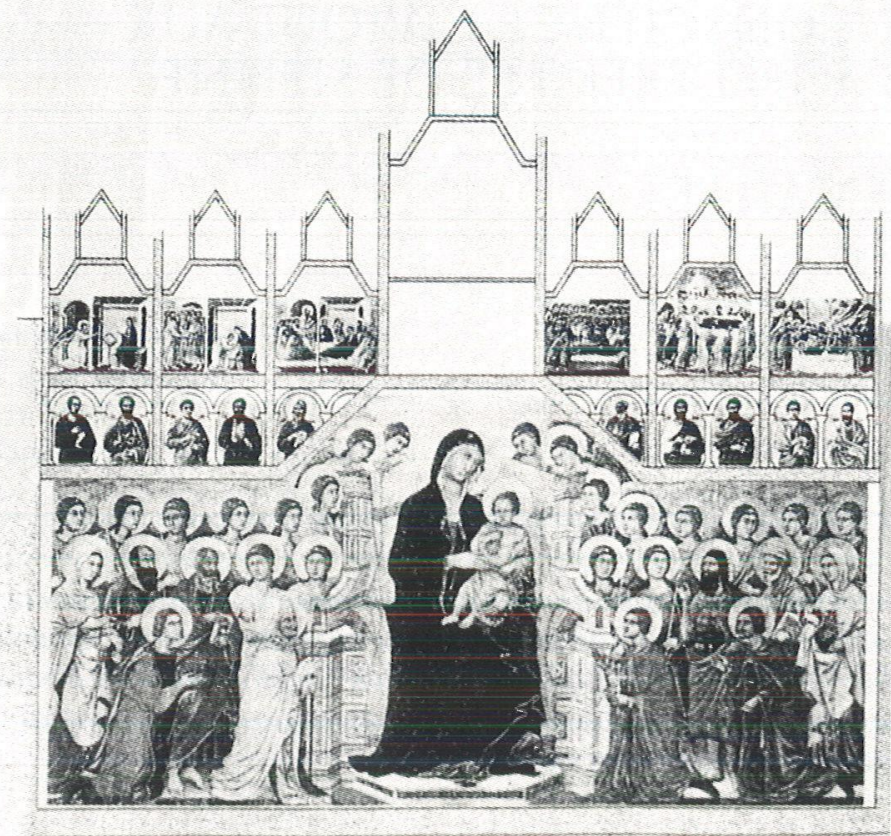

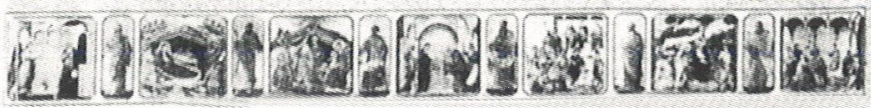

Fig. 2. Cathédrale, retable du maître-autel (Maestà de Duccio, 1308-11): face antérieure (reconstitution d'après J. White).

qu'accostaient des scènes narratives néo-testamentaires plutôt que des figures de saints?

L'équivoque est en tout cas levée avec l'iconographie du vitrail installé en 1287 ou 1288 dans le mur de fond du chevet (fig. 1$)^{8}$. Indépendamment des évangélistes en écoinçons, les quatre patrons précités occupent par paires les deux compartiments latéraux. Ils flanquent, là, un triptyque vertical où se succèdent de bas en haut la Dormition, l'Assomption et le Couronnement de la Vierge. Certes, la délimitation systématique des champs par des bandes ornementales, et la non moins stricte frontalité des quatre saints, détournent d'envisager leur implication directe dans les événements qu'illustre la bande axiale. Mais la simple proximité de cette glorification finale de la Mère de Dieu n'en apparaît pas moins significative; et le fait que cette association s'opère à un emplacement majeur - à la source de lumière principale du choeur liturgique - en renforce encore la portée.

Il revenait au nouveau retable monumental, peint pour le maître-autel par Duccio de 1308 à 1311, d'introduire les quatre patrons de plain-pied dans l'univers marial (fig. 2) ${ }^{9}$. De gauche à droite, Ansanus, Savinus, Crescentius et Victor - ce dernier ayant désormais supplanté Barthélemy - apparaissent agenouillés de part et d'autre du trône de la Vierge. Contrairement à ce qui était jusque là de règle, l'unification spatiale du champ principal érige les personnages latéraux en participants réels de la théophanie; l'éloquence des regards et des mains levées vers Marie le confirment bien. Mais au sein de cette vision globale, les patrons locaux se démarquent nettement: car si les anges et les autres saints se tiennent tous debout, eux seuls traduisent par la génuflexion l'insistance de leur prière et la profondeur de leur vénération. Et leur situation au tout premier plan manifeste non moins clairement le lien qu'ils établissent entre la cité et les puissances suprêmes: on n'oubliera pas non plus que c'est cette face-ci du retable qui s'offrait à la vue des fidèles rassemblés dans la nef; et l'inscription du marchepied du trône - Mater sancta Dei sis causa Senis requie $i^{10}$ — correspond bien à une adresse transmise par ceux

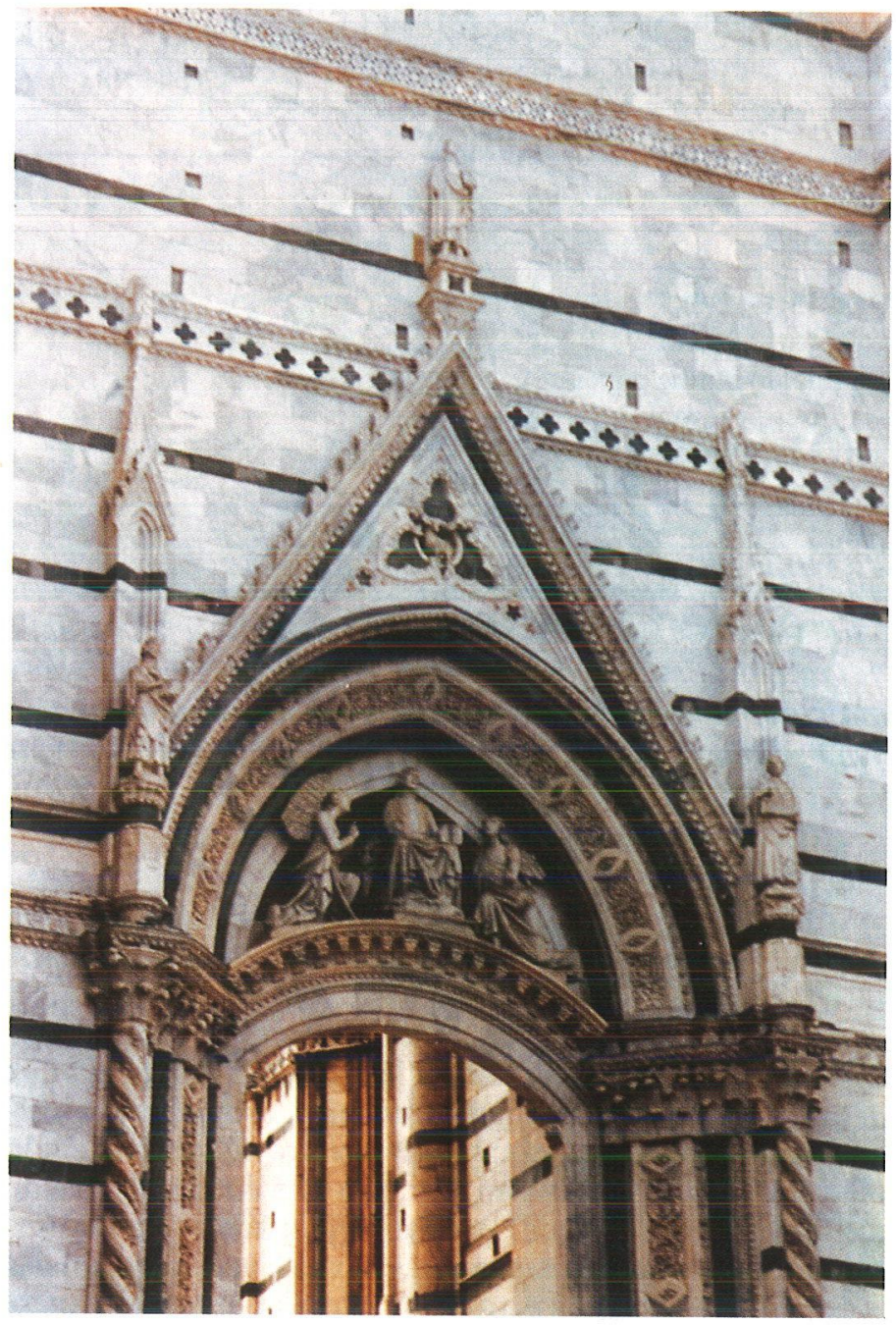

Fig. 3. Cathédrale, portail du collatéral est du Duomo nuovo (par Giovanni d'Agostino, vers 1340) : vue d'ensemble.

qu'un statut privilégié prédisposait à ce soin. Enfin, l'immixtion des quatre patrons dépasse dans cette oeuvre la seule sphère de la Reine des Cieux: car en conjuguant l'exaltation de celle-ci en tant qu'instrument de l'Incarnation (à l'avers) à la commémoration du Sacrifice rédempteur (au revers), le programme de ce retable renvoie à l'économie du Salut dans son entier.

C'est une préoccupation du même ordre qui, de manière plus ramassée, va d'ailleurs aussi s'exprimer dans les années 1340 au portail sculpté par Giovanni d'Agostino pour le collatéral est du Duomo nuovo ${ }^{11}$ (fig. 3). Un Christ en gloire, là, organise depuis le tympan l'ensemble de la composition; et, en partie haute, une Salutation angélique suffit à rappeler l'étape capitale de l'Incarnation. Seules s'associent à cette évocation synthétique les figures des patrons locaux; et, suivant un modèle qui s'imposera vite à l'époque, ceux-ci tiennent dans leur main une maquette de la ville (fig. 4): ainsi s'affirme, par un procédé particulièrement concret à présent, leur rapport étroit avec la communauté. Le caractère hautement suggestif de la formule, notons-le encore, ne pâtissait nullement d'un emplacement secondaire: le portail en question se trouvait en effet au débouché d'une rue menant par l'un des chemins les plus courts au coeur laïc de la cité (le Campo, place du palais communal) ${ }^{12}$; et la nouvelle ouverture ainsi ménagée aurait donc constitué, si le grandiose projet de remodelage avait abouti, l'un des accès principaux à la cathédrale.

Vers ces mêmes années, et en relation précisément avec le projet d'extension vers le Sud ${ }^{13}$, le niveau du choeur était 


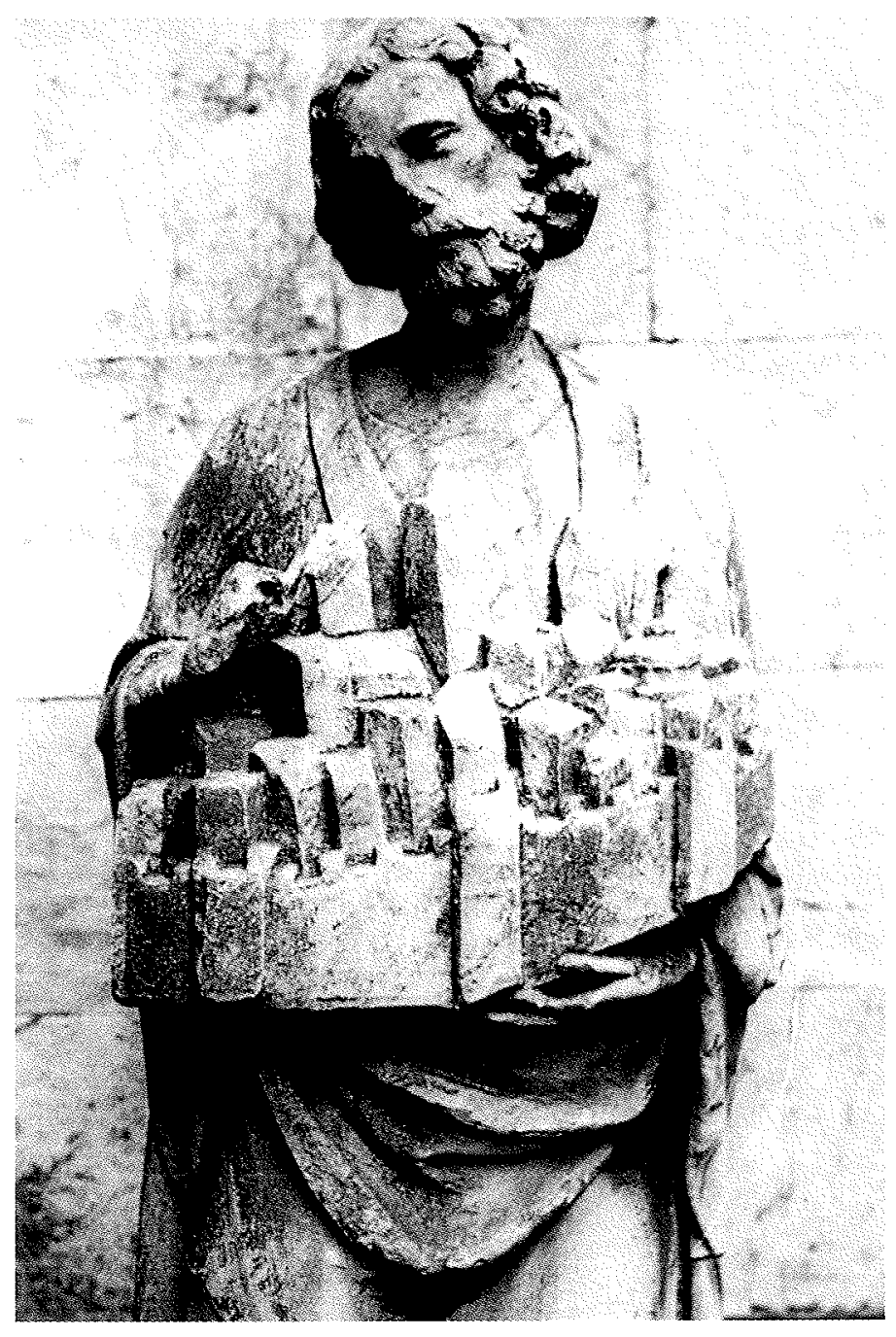

Fig. 4. Cathédrale, portail du collatéral est du Duomo nuovo (par Giovanni d'Agostino, vers 1340): détail d'un des saints patrons locaux.

abaissé à celui de la nef. L'opération supposait l'abandon de la crypte - dispositif d'ailleurs suranné, en cette phase déjà tardive de l'architecture médiévale - par les saints patrons; leurs reliques étaient transférées des deux côtés du choeur, et placées dans quatre nouveaux autels: ceux de Savinus et d'Ansanus an Nord, et ceux de Crescentius et de Victor au Sud ${ }^{14}$. Ils s'offraient ainsi en pleine lumière à la vénération des fidèles, simultanément à la Vierge de l'autel majeur dont, pour la première fois, ils se voyaient rapprochés autrement que parl'image (fig. 5). On songea alors assez vite à pourvoir ces autels de leurs propres retables. Ceux-ci devaient plus tard être déplacés et, pour trois d'entre eux, démembrés; mais les sources textuelles des XIVè-XVè s. permettent d'en reconstituer l'aspect d'origine $^{15}$. Il s'agissait d'abord de l'Annonciation de Simone Martini et Lippo Memmi aujourd'hui aux Offices à Florence, et où les figures en pied de saint Ansanus et - probablement - sainte Marguerite flanquent encore la scène principale. Cette première réalisation, datée de 1333 , a été suivie par deux autres de formule analogue en 1342: une Naissance de la Vierge (aujourd'hui au Musée de l'Oeuvre de la cathédrale à Sienne même) due à Pietro Lorenzetti, et originellement accostêe de saint Savinus et de l'apôtre Barthélemy; et une Présentation de Jésus au Temple (aujourd'hui aux Offices à Florence) par Ambrogio Lorenzetti, avec saint Crescentius et l'archange Michaël de part et d'autre. Quant au quatrième retable, il est désormais assuré qu'on peut le reconnaître dans une Nativité à peu près contemporaine (aujourd'hui au Fogg Art Museum à Cam-

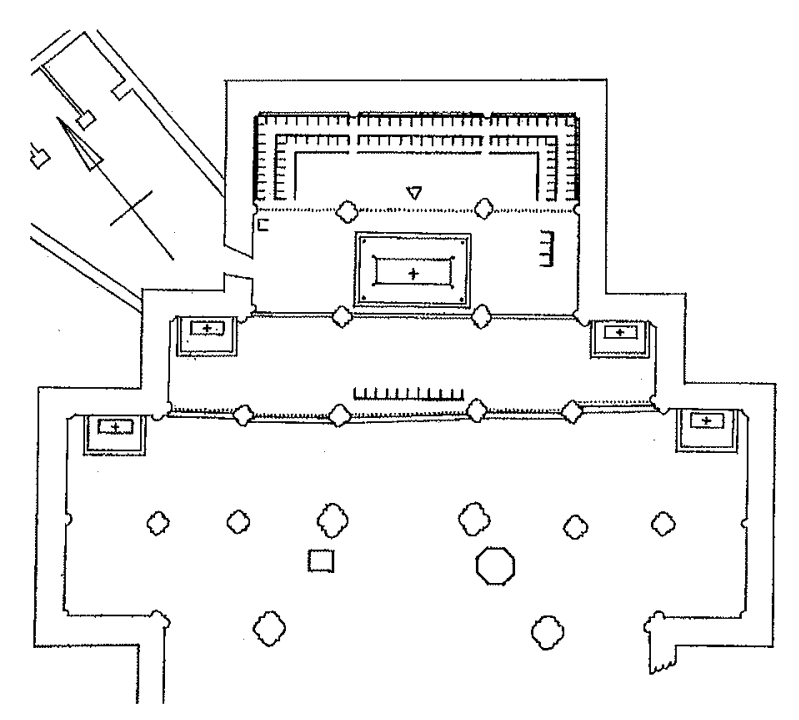

Fig. 5. Cathédrale, schéma de disposition des autels dans le choeur vers le milieu du XIVe siècle (d'après K. Van der Ploeg).

bridge, Mass.) attribuée à Bartolommeo Bulgarini, et qu'accostaient un Saint Victor et une Sainte Catherine d'Alexandrie conservés à Copenhague ${ }^{16}$. Chacun de ces quatre retables, comme on le constate, associait l'un des patrons à un des grands saints vénérés à l'époque (ou à l'apôtre auquel la ville avait depuis longtemps manifesté un particulier attachement); et, plus encore, un lien s'y établissait avec l'une des phase essentielles de la vie de la Vierge jusqu'à l'Incarnation. La liturgie renforçait naturellement ce lien, puisque les avocats de la cité se trouvaient ainsi tour à tour présents lors de la célébration des fêtes mariales correspondantes ${ }^{17}$; et l'implication mariale intervenait, à l'inverse, lors de la célébration des fêtes des quatre patrons. On relèvera également, par ailleurs, le parfait enchaînement de ce programme avec celui du vitrail évoqué ci-avant: les patrons de la ville accompagnent Marie du début de son existence jusqu'à sa fin et à son apothéose (respectivement, à l'entrée et au fond du choeur); et cette double suite narrative contrebalance de manière non mons appropriée les théophanies de l'autel majeur et du portail des années 1340 , où s'immiscent aussi les saints patrons.

Si l'on se transporte à présent au palais communal, l'examen doit être mené en considérant séparément les salles d'exercice des différents rouages du pouvoir, puis les lieux de dévotion: ces pièces avaient en effet leurs spécificités fonctionnelles; et il importe d'envisager la manière dont s'est constitué dans chacune d'elles un programme cohérent. Les études précédentes d'E.C. Southard puis de G. Borghini ${ }^{18}$ offrent ici les bases solides sur lesquelles nous nous appuierons.

Parmi les lieux d'exercice du pouvoir, il faut d'abord faire mémoire d'une salle de réunion du Conseil antérieure à l'érection du palais actuel, et aujourd'hui disparue; pour cette pièce, les documents d'archives font état de la représentation d'une Vierge accompagnée de saints (non nommés), peinte par un certain Mino ${ }^{19}$ : il s'agit là, semble-t-il, de la première réalisation à sujet religieux au siège même du gouvernement civil de Sienne.

La salle du Conseil (dite plus tard "de la Mappemonde") établie ensuite au premier étage a, pour sa part, reçu très vite des peintures relatives aux accroissements et à la défense du territoire de la citée ${ }^{20}$ certaines étaient déjà achevées en 1314, 


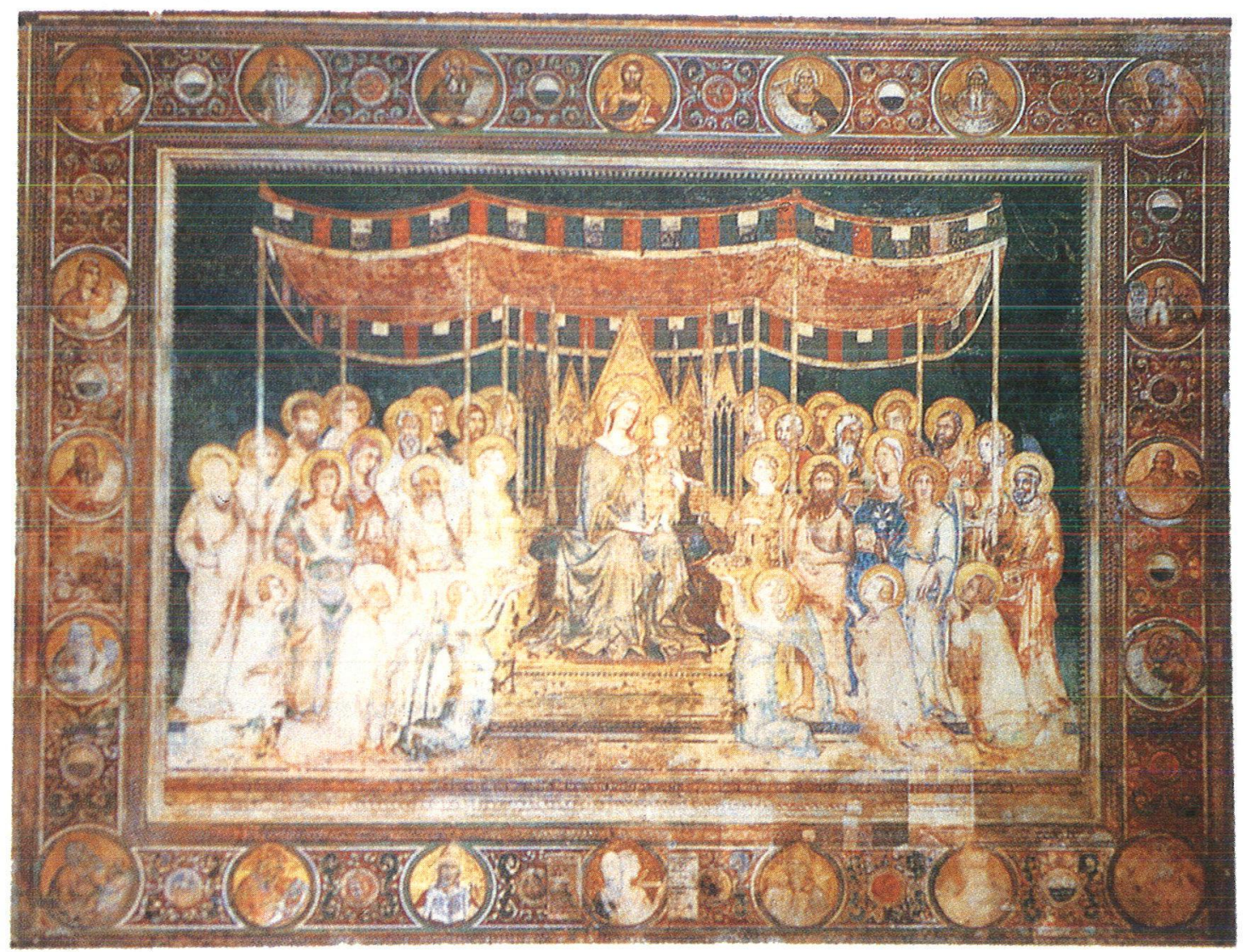

Fig. 6. Palais communal, salle du Conseil ("de la Mappemonde") : Maestà de Simone Martini (1312-15).

et une coïncidence chronologique presque parfaite s'établit ainsi avec la Maestà peinte par Simone Martini en 1312-1315 sur toute la largeur du mur d'un des petits côtés (fig. 6) ${ }^{21}$. Cette composition reprend, comme on l'a maintes fois relevé, l'essentiel de l'iconographie de la Maestà de Duccio à la cathédrale (voir ci-avant, et fig. 2), avec en particulier les quatre saints patrons agenouillés au premier plan. On n'a pas manqué non plus de s'arrêter aux innovations en rapport avec le caractère de cette salle. Dans la bordure, en premier lieu, les écussons blanc et noir (couleurs de Sienne) et au lion rampant (emblème du gouvernement populaire) alternent avec les bustes du Christ, des évangélistes, des prophètes, et des docteurs de l'Eglise; s'y trouvent également incluses les reproductions des sceaux de la ville et du Capitaine du peuple;

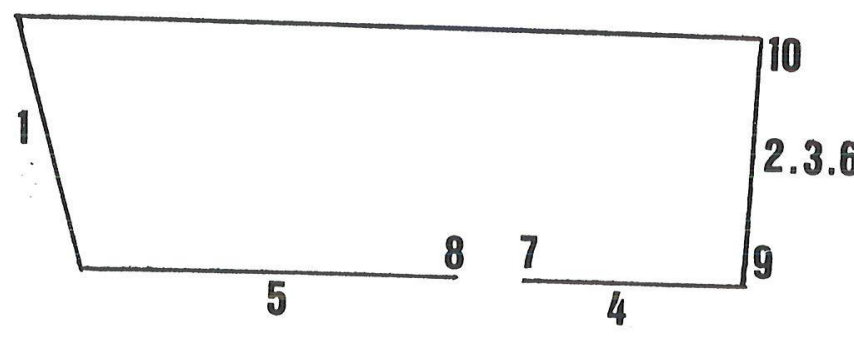

Fig. 7. Palais communal, salle du Conseil ("de la Mappemonde"): schéma de distribution des peintures réalisées entre le début du XIVe et le début du XVIe s. 1. Maestà de Simone Martini 2. Cession pacifique d'un bourg du contado 3. Guidoriccio da Fogliano 4. Bataille de Val di Chiana 5. Bataille de Poggio Imperiale 6. "Mappemonde" d'Ambrogio Lorenzetti 7. Saint Bernardin 8. Sainte Catherine de Sienne 9. Saint Victor 10. Saint Ansanus en outre, la double personnification de l'Ancienne et de la Nouvelle Loi, circonscrite par les noms des vertus cardinales et théologales, s'y accompagne du revers d'une monnaie avec l'audacieuse formule Sena Vetus Civitas Virginis. Alfa at Omega. Principium et Finis. Dans le champ même, le texte du rouleau tenu par le Christ-Enfant - injonction aux gouvernants d'aimer la justice ${ }^{22}$ - et les inscriptions sur les marches du trône - dialogue entre les patrons, qui se plaignent des propos et agissements de certains, et la Vierge, qui les assure qu'elle n' exaucera de prière qu'en faveur de ceux qui font régner l'équité23 - ne jouent pas un moindre rôle dans ce que l'on a justement considéré comme une véritable laïcisation du thème. E.C. Southard a encore attiré l'attention sur une sorte de réciprocité des bénéfices exprimée dans ce tableau: car si la Vierge protège

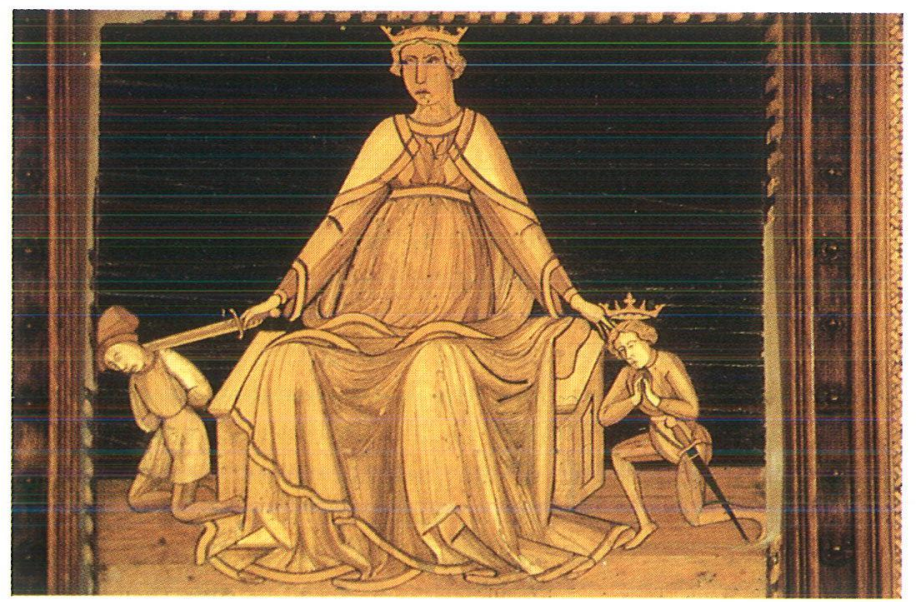

Fig. 8. Palais communal, salle du Conseil ("de la Mappemonde"), dossier du siège des magistrats : allégorie de la justice (par Mattia di Nanni, 1426). 


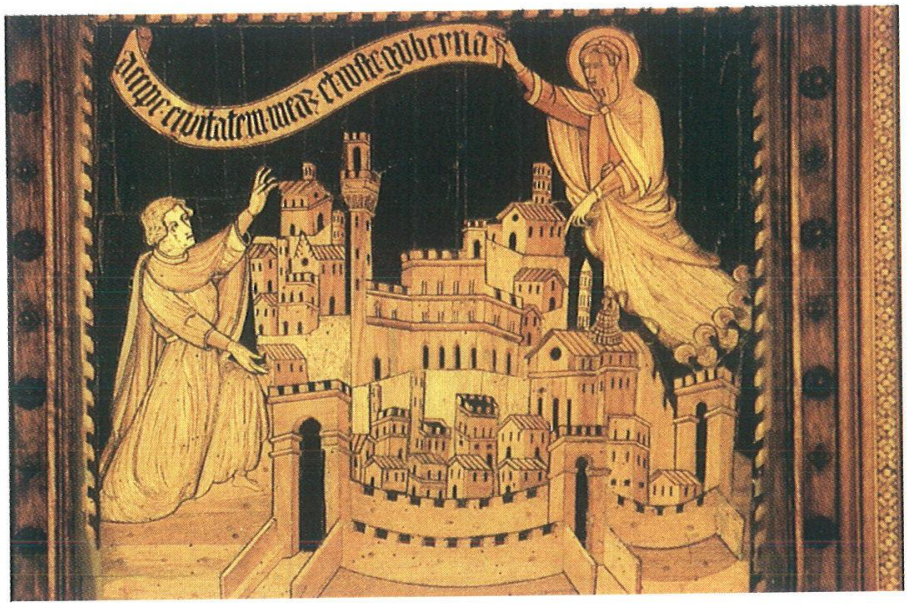

Fig. 9. Palais communal, salle du Conseil ("de la Mappemonde"), dossier du siège des magistrats : Vierge remettant la ville au Podestà (par Mattia di Nanni, 1426).
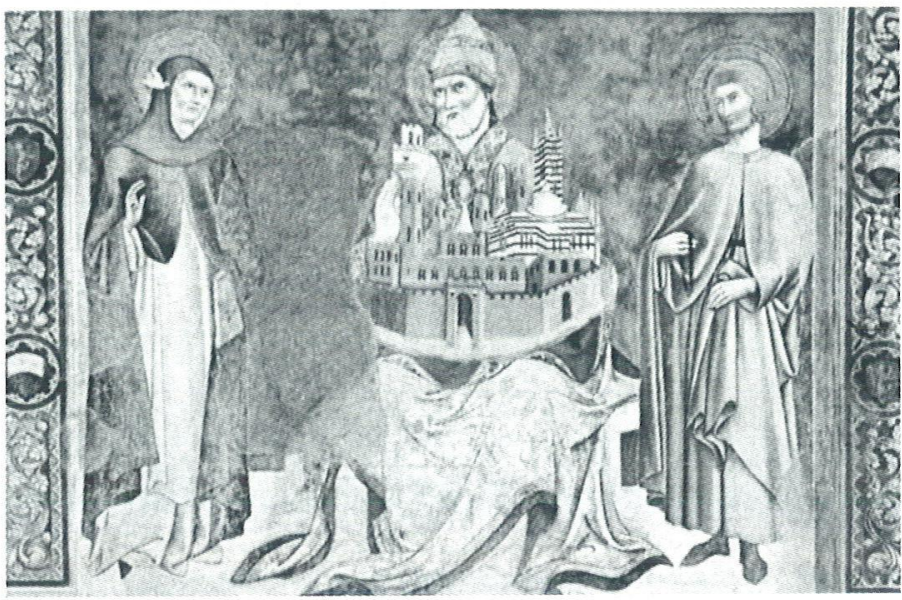

Fig. 10. Palais communal, salle principale de la Biccherna au rez-de. chaussée: saint Pierre d'Alexandrie tenant la maquette de Sienne, accosté des bienheureux Andrea Gallerani et Ambrogio Sansedoni (par Sano di Pietro, 1446).

la ville, celle-ci lui offre l'abri d'un baldaquin à ses couleurs ${ }^{24}$. Nous voudrions quant à nous surtout revenir à quelques aspects en apparence formels, mais tout aussi déterminants pour l'affirmation de cet esprit civique. Il s'agit d'une part de la représentation de Marie comme souveraine terrestre, avec une couronne à fleurons et un manteau brodé d'or agrafé par un fermail lui-même très ouvragé: une telle parure se démarque à dessein de celle de la Reine des Cieux proposée par le modèle de Duccio (et à laquelle Simone Martini ne manquera d'ailleurs pas de revenir pour figurer Marie dans le cadre de l'Histoire Sainte ${ }^{25}$ ). D'autre part, la disposition du groupe sous le baldaquin, dont les lignes de fuite suggèrent fort efficacement la profondeur du champ, détone tout autant par rapport aux schémas courants de l'époque: cette perspective résolument tridimensionnelle, ainsi que le fond bleu substitué à l'habituelle plage d'or, s'accordent en revanche tout à fait aux architectures, aux paysages et au fond des compositions voisines (cf. schéma fig. 7): à savoir, le tableau de la cession pacifique d'un bourg du contado (vers 1314, et donc contemporain de la Maestà) ${ }^{26}$; puis le Guidoriccio da Fogliano à Montemassi (vers 1330) ${ }^{27}$; et plus tard encore les scènes de bataille de Val di Chiana $(1363)^{28}$ et de Poggio Imperiale (1480) ${ }^{29}$. Une

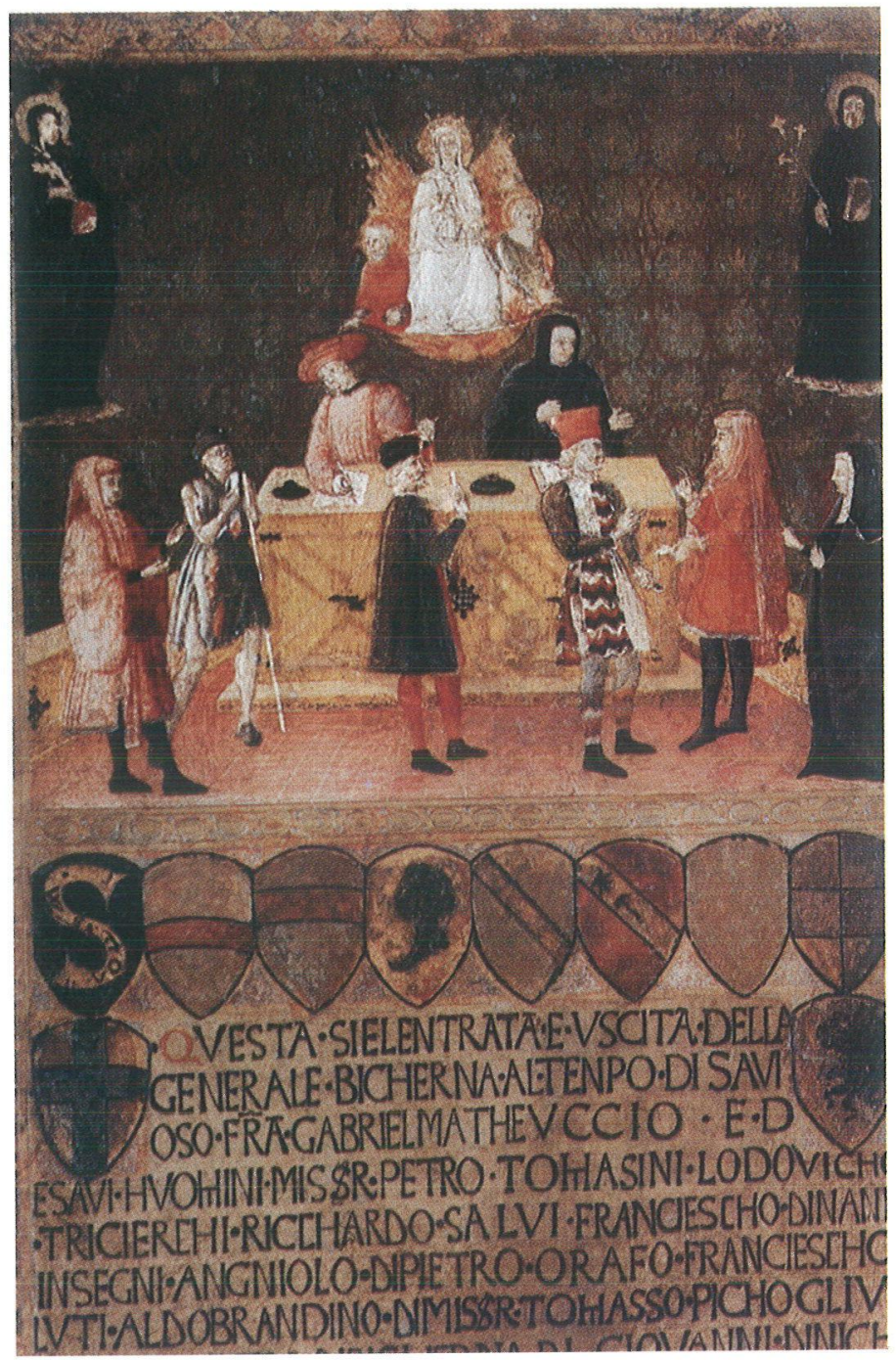

Fig. 11. Couverture d'un registre de la Biccherna en date de 1452 : vue de l'office la Biccherna, avec l'image de la Vierge glorieuse et de deux bienheureux servites (peintre inconnu).

réelle unité s'établit de la sorte sur tout le pourtour de la salle; et cela traduit au mieux que la Vierge en personne, sollicitée par les saints patrons, préside à ces victoires et impose sa loi aux pays soumis. A ce sujet encore, on n'omettra pas de rappeler la mise en place vers $1340 / 45$, vis-à-vis et donc sous le regard de Marie, du disque de la "Mappemonde" où Ambrogio Lorenzetti avait vraisemblablement représenté - en les insérant dans une cosmographie? - les diverses composantes de l'Etat siennois ${ }^{30}$. Un autre complément notable au programme de cette salle devait être offert sur le dossier du siège marqueté, commandé à Mattia di Nanni en 1426 et sans doute destiné, juste sous la Maestà de Simone, aux magistrats euxmêmes ${ }^{31}$; l'un des panneaux y montre une allégorie de la justice (fig. 8), et répond ainsi à la phrase inscrite sur le rouleau du Christ-Enfant (cf. ci-avant); et un autre panneau s'insère tout autant dans la logique de l'ensemble puisqu'il présente la Vierge remettant la ville au juste gouvernement du Podestà (fig. 9) ${ }^{32}$. Pour en terminer, enfin, avec les adjonctions antérieures au XVIè s., il faut signaler, de part et d'autre de l'accès au vestibule de la chapelle (cf. schéma fig. 7), les représentations en pied de saint Bernardin et sainte Catherine de Sienne, peintes par Sano di Pietro et Vecchietta en 1460-6133; avec ces deux 


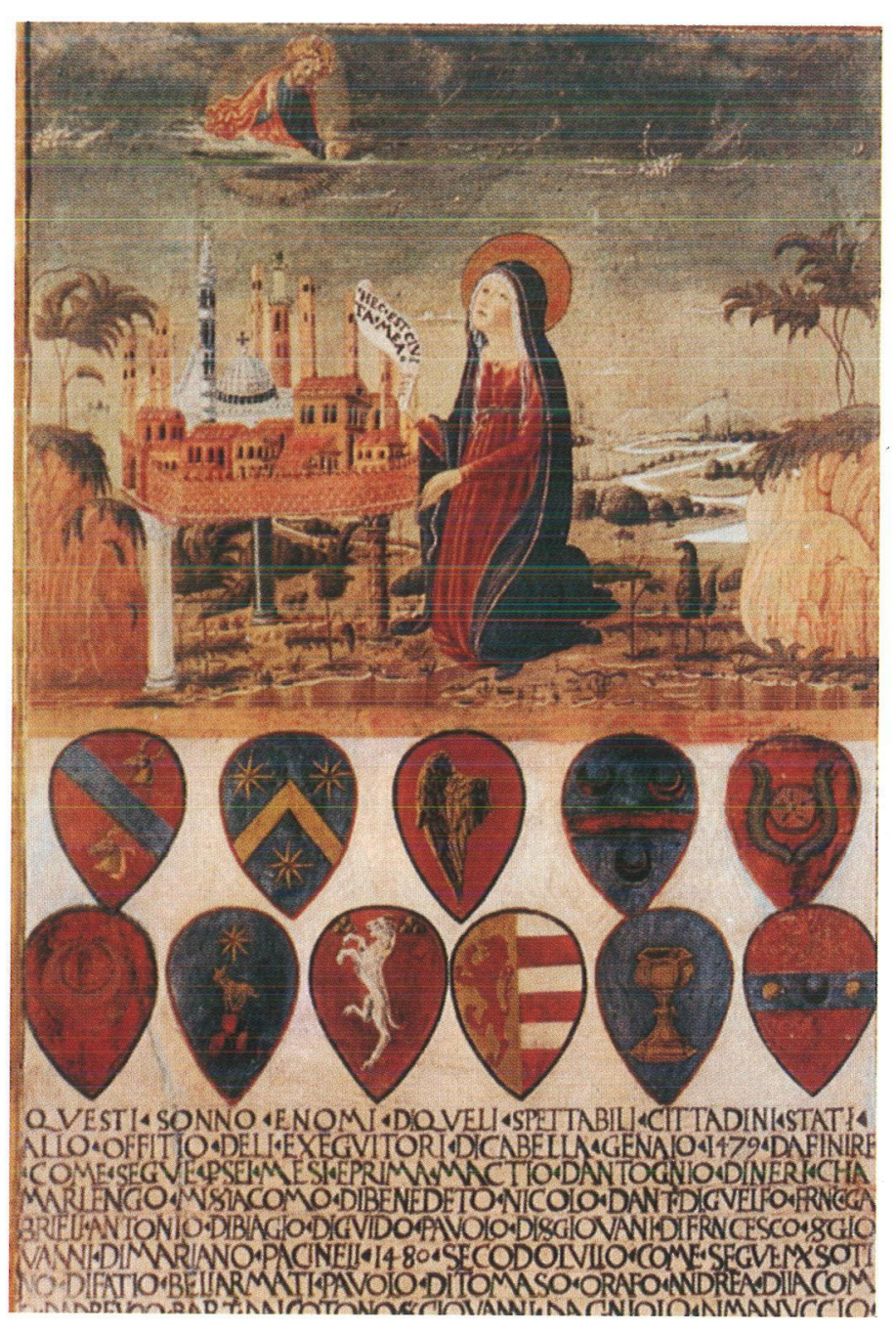

Fig. 12. Couverture d'un registre de la Gabelle en date de 1480 : Vierge recommandant la ville au Christ dans les cieux (par Neroccio di Bartolommeo de' Landi).

personnages, respectivement canonisés en 1450 et $1461^{34}$, se manifeste désormais le poids des saints récents et dont l'existence s'est déroulée dans le cadre même de la cité.

Les salles du rez-de-chaussée et du premier étage dévolues aux services financiers (Biccherna) ont également été pourvues très tôt d'un décor pictural: les archives de 1293 et 1295 font en effet état de paiements pour la représentation des armes d'un Podestà puis celle - en pied? - d'un de ses successeurs ${ }^{35}$; en 1306, Segna di Bonaventura y livrait une tavola dipinta (de sujet non précisé); et en 1323, Simone Martini y peignait un Saint Christophe avec les armes du Podestà du moment ${ }^{36}$. La pièce principale de cet office ${ }^{37}$ conserve à l'un de ses murs, dans une niche, une peinture de Sano di Pietro en date de 1445 et représentant le Couronnement de la Vierge avec de nombreux anges et saints. En fait, cette composition a été superposée à une autre, de même sujet, due à Lippo Vanni et remontant à $1352^{38}$; l'association de la Commune à la glorification de Marie y était déjà suggérée, sur le chancel en trompe-l'oeil sous-jacent, par cinq écussons aux couleurs de Sienne; elle a été explicitée en 1445 par la formule centrale de la banderole déroulée par deux anges au pied du trône du Couronnement ${ }^{39}$. Et ce lien s'est encore vu renforcé dans les années suivantes avec l'adjonction de part et d'autre, par le même Sano di Pietro, d'une Sainte Catherine de Sienne et d'un Saint Bernardin tenant la maquette de la ville ${ }^{40}$. Ce dernier schéma se retrouve d'ailleurs dans une autre composition de Sano di Pietro datée de 1446, aujourd'hui

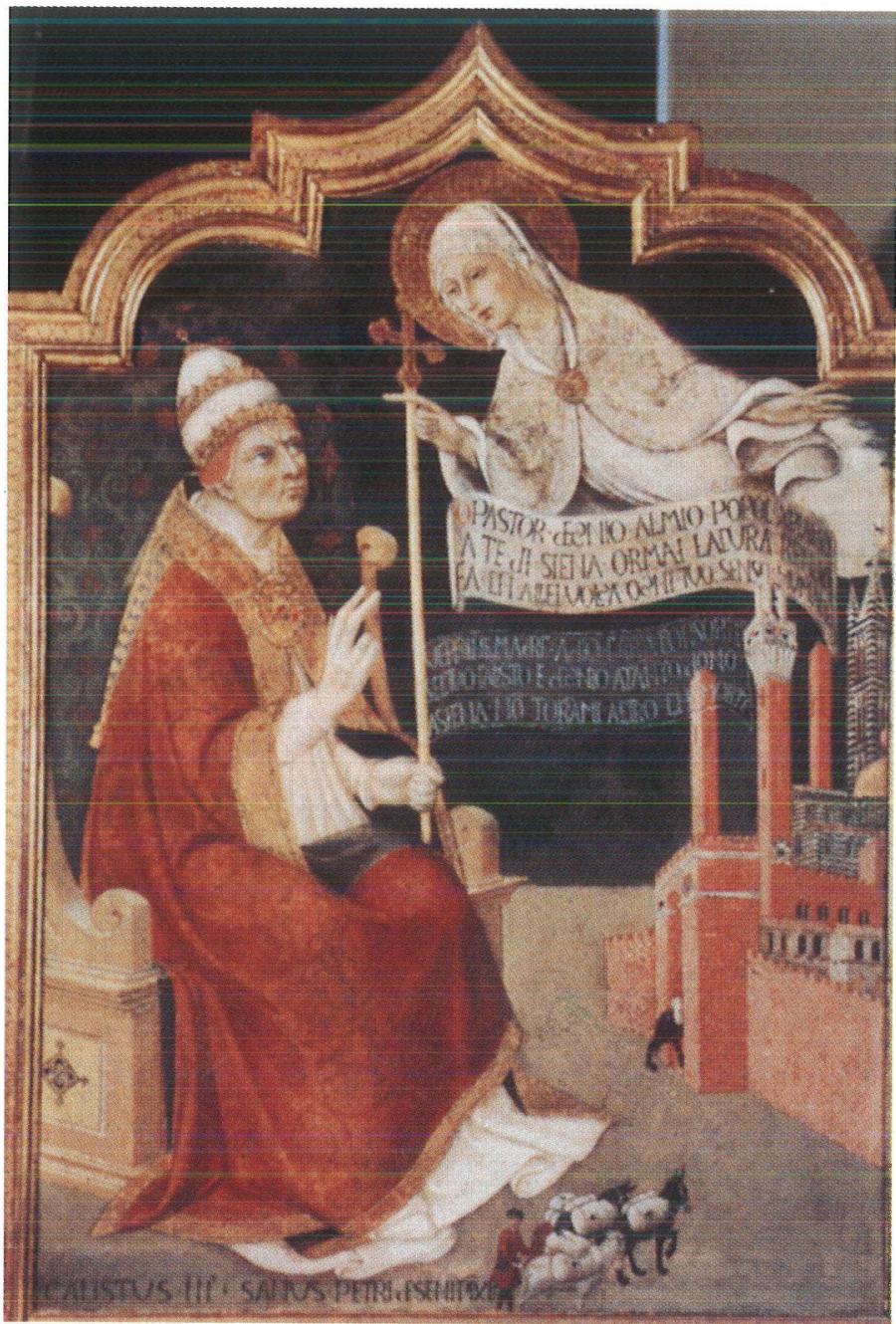

Fig. 13. Palais communal, salle du rez-de-chaussée assignée à l'approvisionnement en grain : apparition de la Vierge au pape Calixte III (par Sano di Pietro, 1456).

extérieure à cette pièce mais qui y était originellement incluse: saint Pierre d'Alexandrie, cette fois, y tient la maquette, accosté des bienheureux Andrea Gallerani et Ambrogio Sansedoni ${ }^{41}$ (fig. 10); Pierre d'Alexandrie s'était vu ériger au nombre des protecteurs particuliers de la cité en 1403 lorsque, le jour de sa fête (26 novembre), avait été mise sur pied une conjuration hostile aux Visconti fortement ingérés dans les affaires siennoises ${ }^{42}$; quant aux deux bienheureux, rappelons qu'il s'agissait respectivement du fondateur de l'hôpital de la confrérie de la Miséricorde et d'un illustre prédicateur dominicain, dont les autorités communales avaient officiellement pris le culte en charge en 1347 et $1329^{43}$. L'iconographie religieuse déployée dans le cadre de la Biccherna s'étend encore aux couvertures des registres dans lesquels, chaque semestre, le camerlingue ou ses proviseurs établissaient les comptes de leur gestion ${ }^{44}$. En effet, la représentation du camerlingue à sa tâche et les armoiries des proviseurs tendent à y laisser place, à partir du XIVè s., à des scènes à caractère civique mais aussi sacré: parmi les spécimens conservés, on relève ainsi une Vierge protégeant la ville (1451), une vue de l'office même de la Biccherna sous l'image de la Vierge glorieuse et de deux bienheureux servites (1452) (fig. 11), et une Vierge protégeant Sienne des séismes récemment survenus $(1467)^{45}$. Ces témoignages s'avèrent donc également révélateurs du souci de placer l'administration d'un service important de la Commune sous les auspices des puissances célestes et des saints. 
Des observations similaires peuvent être faites pour la Gabelle, office ayant pour tâche principale la collecte de l'impôt dans le contado ${ }^{46}$. A l'un des murs, on retrouvait l'un des plus anciens patrons de la ville, Ansanus, peint par Lippo Memmi et Giovanni da Pisa vers 1326; et une composition de Nicola d'Ulisse, en date de 1452, montrait une Assomption avec des anges et divers saints ${ }^{47}$. Quant aux réalisations mobilières, les couvertures des registres de cet office présentent aussi de nombreux sujets religieux: sans se livrer ici à leur énumération exhaustive, on signalera tout particulièrement une Vierge recommandant la ville au Christ dans les cieux (1480) (fig. 12), la remise des clés de la ville à l'autel de la Madonna delle Grazie - plus tard dite del Voto - dans la cathédrale (1483), une Vierge guidant sur les eaux un vaisseau aux couleurs de Sienne (1487), le camerlingue et les administrateurs de la Gabelle en pénitents et priant la Vierge d'entrer dans la ville $(1489)^{48}$; s'ajoute encore à cette liste l'Annonciation de plus grand format peinte par Ambrogio Lorenzetti en 1344, et comportant aussi les noms des administrateurs de la Gabelle pour le second semestre de cette anné $e^{49}$.

La salle du rez-de-chaussée assignée, à partir de 1370, à l'approvisionnement en grain en temps de carence ${ }^{50}$ conserve, dans une niche, une Vierge de Miséricorde peinte par Vecchietta vers 1453-57 ${ }^{51}$; deux des patrons traditionnels de Sienne, Savinus (à gauche) et Ansanus (à droite), s'y mêlent aux autres saints; et une figure féminine couronnée, aux pieds de Marie, pourrait bien être identifiée comme une personnification de la ville ${ }^{52}$; au demeurant, celle-ci s'avère représentée par les nombreux bustes de saints et bienheureux locaux de récente promotion dans les niches en trompe-l'oeil à l'intrados de l'arc ${ }^{53}$; enfin, saint Bernardin, autre récente gloire siennoise, fait pendant à saint Martin partageant son manteau pour flanquer l'ensemble de la composition. A une autre paroi de cette pièce se trouvait encore appendue, auXVIIIè s., une peinture sur bois de Sano di Pietro en date de 1456; aujourd'hui conservée à la Pinacothèque, elle illustre l'apparition de la Vierge au pape Calixte III trônant devant la ville et avec à ses pieds un convoi de grain (fig. 13$)^{54}$ : il s'agit d'une allusion aux secours procurés en 1455 par ce pontife, alors que Sienne se trouvait menacée de famine par les entreprises de Jacopo Piccolomini, condottiere à la solde du roi de Naples; les deux banderoles, où se lisent respectivement l'injonction au pape pour qu'il prenne soin de la cité et la réponse empressée de Calixte, établissent une fois de plus l'indissociabilité du destin de Sienne et de la volonté de Marie, par l'entremise ici du chef de la chrétienté. Et, comme l'ont bien relevé E.C. Southard puis G. Borghini, l'accent ainsi porté sur l'assistance matérielle s'accorde parfaitement avec le thème de la Vierge de Miséricorde et le Saint Martin au pauvre qui l'accoste, et correspond tout autant à la destination de la salle.

Une pièce désignée dans un document de 1461 comme Camera del Capitano, et de localisation non déterminée, avait apparemment reçu une Catherine de Sienne en pied, commandée par les membres du Consistoire au peintre Francesco Migliori le 27 juin de cette même année 1461, soit deux jours avant la canonisation officielle de la sainte ${ }^{55}$. En pendant à cette image, vraisemblablement, un Saint Bernardin devait être ajouté par Nofrio di Fruosino Giusi en $1497^{56}$. Ainsi se trouvaient de nouveau exaltées, ici, les deux grandes figures du mysticisme local de la fin du Moyen âge.

Au dernier étage et à l'arrière du palais, du côté de la place du marché, la grande loggia avait été aménagée pour que les Neuf puissent s'aérer: il leur était en effet interdit, durant tout l'exercice de leur charge et sauf pour les cérémonies publiques, de quitter le bâtiment ${ }^{57}$. Dans une niche du mur de droite (en

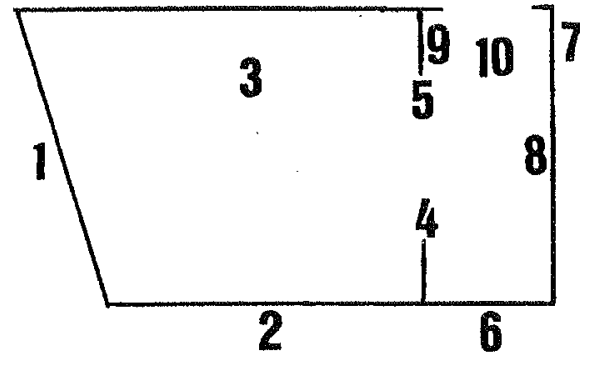

Fig. 14. Palais communal, schéma de distibution des peintures réalisées par Taddeo di Bartolo au début du XVe s. dans la chapelle du premier étage et dans le vestibule (anticappella) qui la précède. 1. Autel, avec Annonciation originellement surmontée du. Couronnement de la vienge 2. Derniers jours de la vio de la Vierge (et saint Jean Baptiste au pilastre médian de cette même paroi) 3. Voûte, écoinçons, paroi et pilastre médian: anges, prophètes, évangélistes inspirant les docteurs de l'Eglise, persomifications des vertus cardinales et theologales, divers saints dont Pierre d'Alexandrio avec un étendarl aux couleurs de la ville 4. Judas Macchabée 5. Ambrogio Sansedoni 6. Saint Christophe 7. Aristote 8. Double triade dhommes illustres de la Rome républicaine (avec aux lunettes sus-jacentes, ot vis-à-vis : personnifications du courage, de la prudence, do la justice, de la magnanimité et de la religion) 9. César et Pompée 10. Vốte d'entrée : carte de la Rome antique, Jupiter; Mars, Apollon et Pallas.

entrant), Ambrogio Lorenzetti a peint avant 1340 une Vierge trônante, présentant de la main droite au Christ-Enfant un globe aux couleurs de la ville ${ }^{58}$; la banderole tenue par Jésus, avec une citation de l'Evangile de Jean $(13,34)$, constitue une injonction expresse pour la bonne entente des magistrats ${ }^{59}$. Les personnifications des quatre vertus cardinales (aujourd'hui disparues) complétaient cette image, en illustrant les principes devant inspirer ces mêmes dirigeants: on avait donc là un écho direct à la théorie des vertus associées à la figure allégorique du Bon Gouvernement dans la Salle de la Paix (ou Salle des Neuf, ou Sala delle Balestre) du premier étage ${ }^{60}$.

Si l'on en vient à présent aux espaces de dévotion, il faut d'abord évoquer la première chapelle des Neuf ${ }^{61}$, sise au rezde-chaussée. Duccio y avait réalisé en 1302 un retable marial ${ }^{62}$, aujourd'hui perdu. Simone Martini y avait peint ensuite vers 1321, probablement sur le mur derrière l'autel, une Crucifixion (également disparue) ${ }^{63}$. Ce décor devait être complété vers la fin du XIVè s., à la voûte, par un buste du Christ bénissant entouré d'anges attribué à Bartolo di Fredi; dans le même temps (1390), une Annonciation avec les saints Antoine et Thomas d'Aquin ainsi que le bienheureux siennois Andrea Gallerani étaient peints - par Andrea di Bartolo ? - près de la porte menant à l'intérieur du palais; comme l'a souligné E.C. Southard, ces trois figures personnifiant la pureté de vie, la science divine et la charité offraient des exemples particulièrement appropriés aux gouvernants dans leur recueillement religieux.

La seconde chapelle, au premier étage, a été aménagée en 1404/06 lorsque l'on a décidé de convertir celle du rez-dechaussée en bureau ${ }^{64}$. Indépendamment d'un retable marial plus ancien à l'autel - retable remplacé lors de la rénovation de la niche en 1686, et aujourd'hui disparu —, la décoration picturale est due à Taddeo di Bartolo et a été réalisée dès 1406/ $07^{65}$. Une Annonciation se dispose de part et d'autre de l'autel, que surmontait encore un Couronnement de Marie ${ }^{66}$. Les derniers jours de la Vierge sont illustrés en quatre panneaux au mur latéral gauche, avec saint Jean Baptiste sur le pilastre articulant cette même paroi. Des anges, des prophètes, les évangélistes inspirant les docteurs de l'Eglise, les personnifications des vertus cardinales et théologales, et divers autres saints dont 


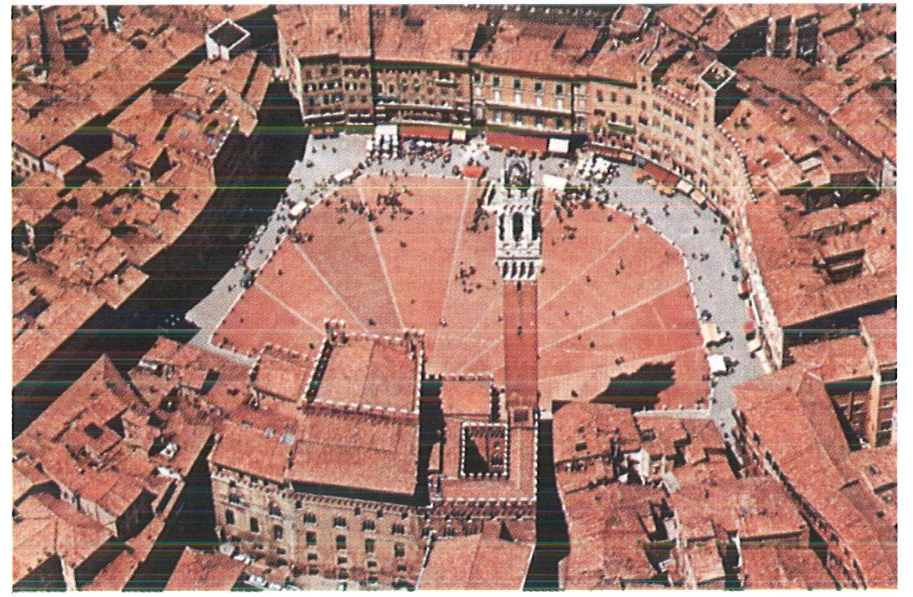

Fig. 15. Vue du Campo, avec au premier plan le palais communal.

Pierre d'Alexandrie tenant un étendard aux couleurs de la ville, complètent cette ensemble à la voûte et au mur de droite. Aux deux piles de l'entrée, enfin, se font face Judas Macchabée et le bienheureux siennois Ambrogio Sansedoni; comme l'a noté E.C. Southard, le rapprochement entre ces deux personnages se justifiait dans la mesure où ils offraient également l'exemple du patriotisme: car si le héros biblique évoquait la résistance à la monarchie hellénistique, le prédicateur local était intervenu en 1273 pour faire lever la condamnation pontificale que subissait Sienne pour ses sympathies gibelines antérieures. Quant au reste du décor de cette chapelle, une nouvelle touche civique devait s'y ajouter avec les stalles marquetées exécutées par Domenico di Niccolo "dei Cori" entre 1415 et $1426^{67}$ : les panneaux des dossiers y illustrent en effet les actes du Credo des apôtres, surmontés par des écussons aux couleurs de Sienne.

L'anticappella, correspondant au couloir de transition avec la sacristie, est souvent plutôt considérée comme un passage entre la salle du Conseil et le Consistoire: son programme a donc été jugé relatif à la fonction civile de ces pièces, plutôt qu'à celle de la chapelle ${ }^{68}$; mais cette interprétation peut, semble-til, être discutée. Certes, et indépendamment d'un Saint Christophe apotropaïque en date de 1408 au mur de fond, Taddeo di Bartolo y a peint en 1414 des sujets profanes,

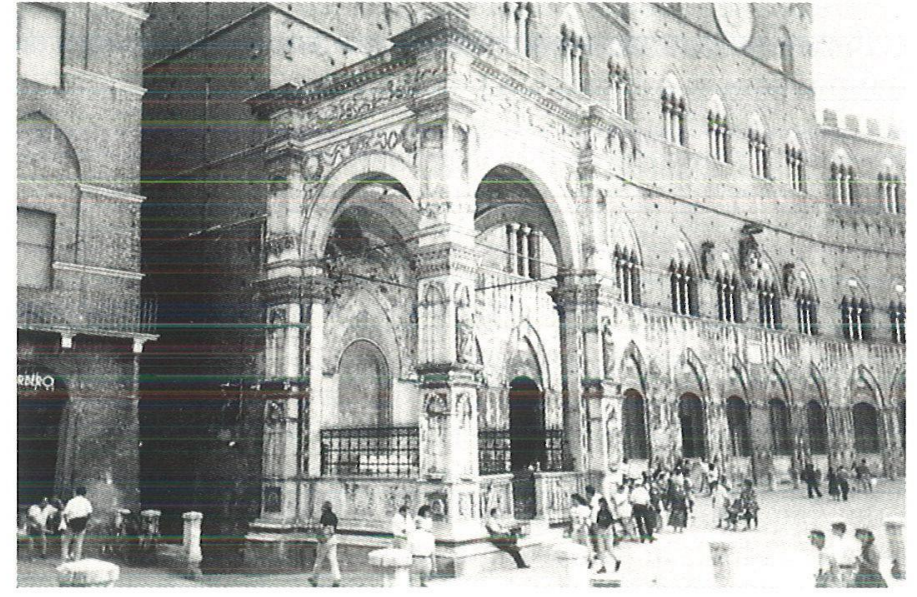

Fig. 16. Façade du palais communal : Cappella di Piazza.

voire franchement païens: Aristote et deux triades d'hommes illustres de la Rome républicaine opposés à César et Pompée aux murs latéraux; les personnifications du courage, de la prudence et de la justice, ainsi que de la magnanimité et de la religion, aux lunettes; une carte de la Rome antique accostée de Jupiter, Mars, Apollon et Pallas à la voûte. Récemment, D. Hansen a fort bien mis en lumière la logique de cet ensemble, sans doute inspiré par les deux juristes Cristoforo d'Andrea et Pietro de' Pecci69: il s'agit d'une traduction figurative du Corpus iuris civilis, avec Aristote correspondant à l'introduction générale des Institutions, les Vertus aux principes abstraits du Digeste, les triades de héros républicains aux cas concrets des Causes, et les textes en langue vernaculaire (explicitant les exemples offerts par les personnages des deux triades) à l' "actualisation" des Novelles; quant aux quatre divinités et à la carte de l'Urbs, leur présence s'explique justement par l'un de ces textes, qui enjoint aux Siennois de demeurer unis pour ne pas, à l'instar des anciens Romains que leurs vertus avaient élevés jusqu'aux cieux mais dont les factieux César et Pompée avaient causé la chute, subir un sort funeste. L'intention générale s'avère donc indiscutablement politique, mais la disposition en ouverture vers la chapelle par une large baie in-

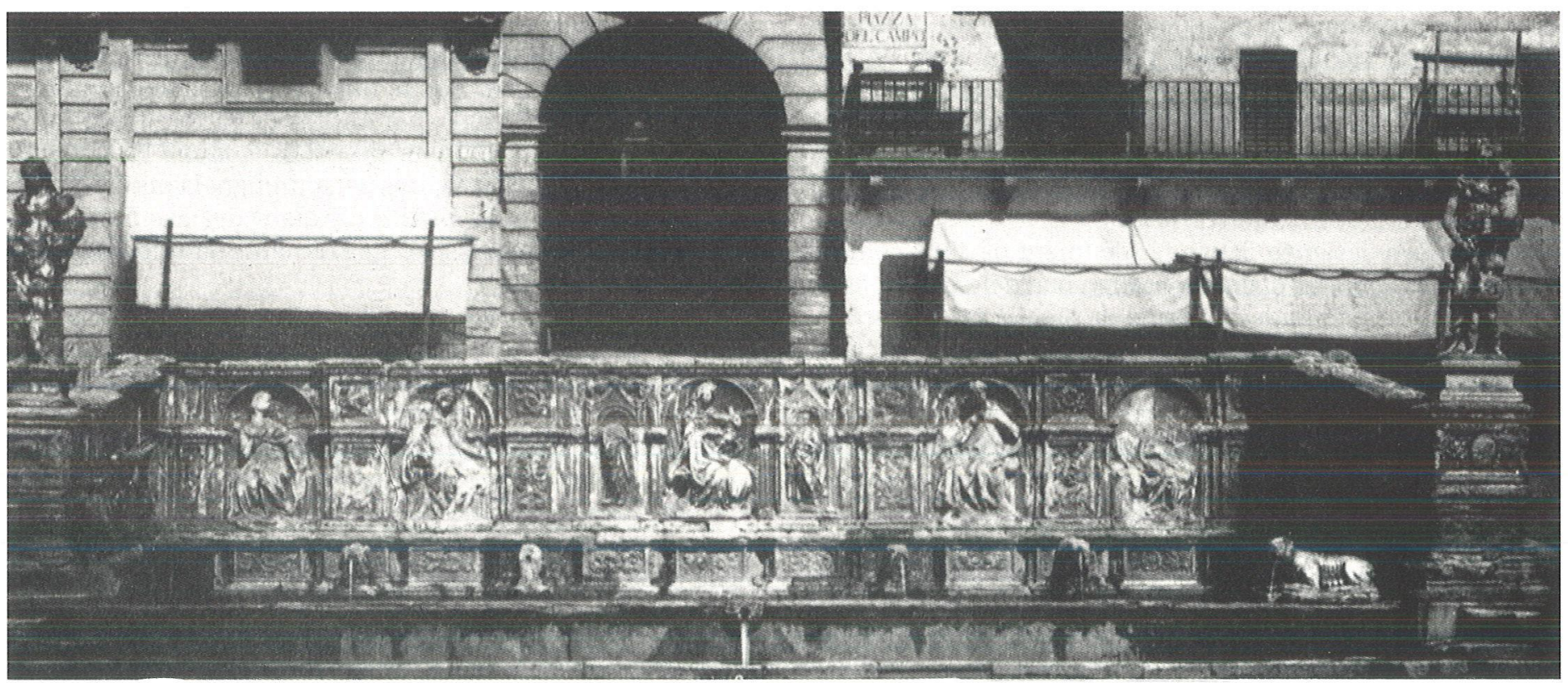

Fig. 18. Campo, fontaine monumentale dite Fonte Gaia (par.Jacopo della Quercia, 1414-19). 


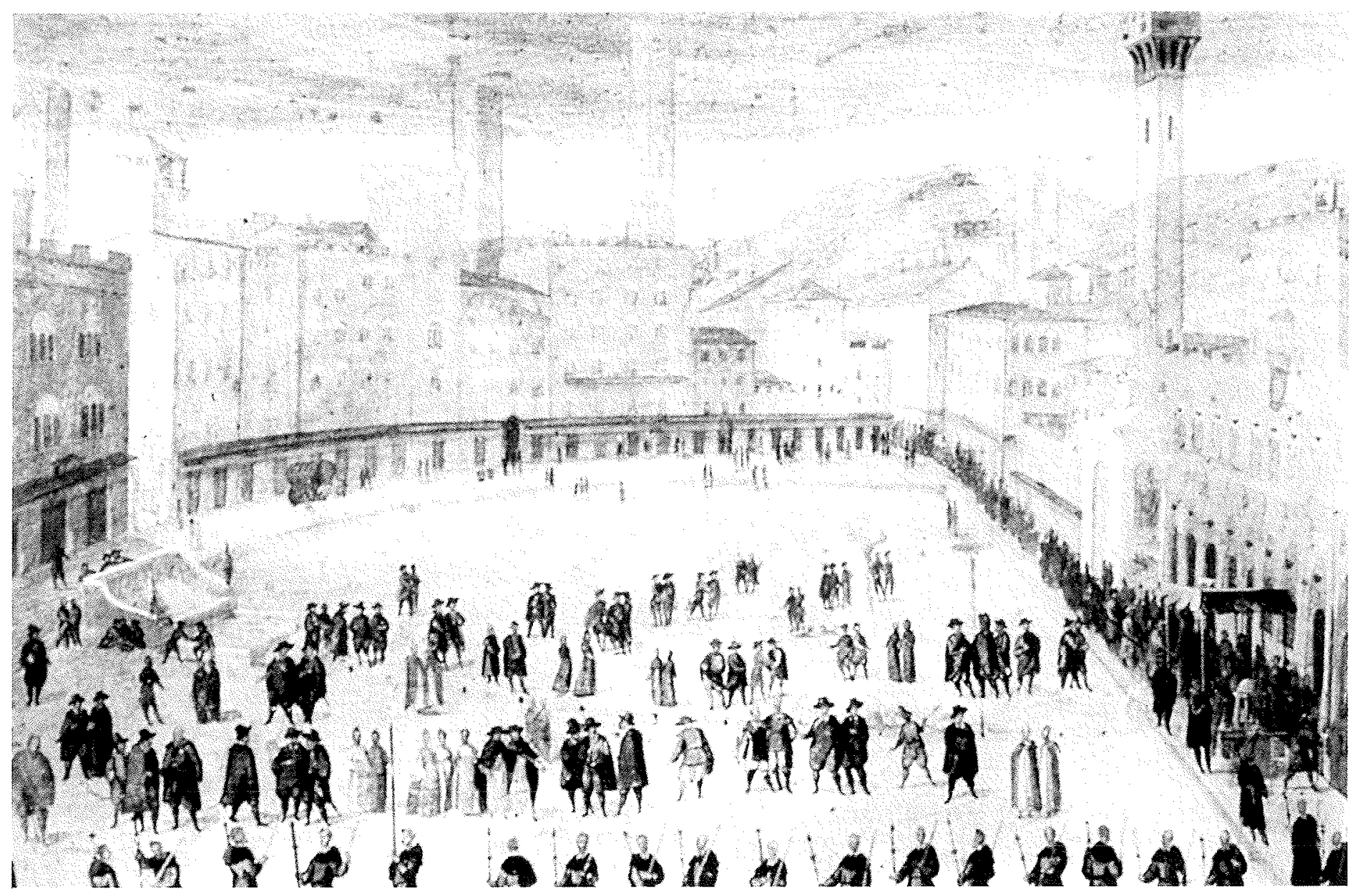

Fig. 17. Détail d'une converture de registre de la Gabelle en date de 1609, montrant le Campo avec à gauche, face au palais communal, la Fonte Gaia.

cite à relier les deux programmes, tout comme ceux d'une église et du "narthex" qui la précède (cf. schéma fig. 14); on peut alors envisager cette thématique tirée de l'histoire comme une propédeutique aux réalités célestes dévoilées dans le sanctuaire: la pratique des vertus civiles qu'exaltait l'iconographie du vestibule constituait, pour les magistrats, la condition nécessaire pour gagner à leur cause la Divine Protectrice.

La place du Campo (fig. 15), devant le palais, se trouvait en étroite relation avec ce dernier: en témoigne, indépendamment même de la proximité immédiate, la subdivision du dallage en un nombre de compartiments égal à celui des neuf magistrats. Mais cet espace n'en constituait pas moins une entité distincte; et, dans la mesure où il s'agissait du lieu de rassemblement majeur pour les citoyens, on conçoit sans peine que la religion civique ait aussi dû le marquer de son empreinte. Une étape importante à cet égard a été franchie après la grande peste de 1348, lorsque les gouvernants ont décidé d'ériger sur la façade même du palais une chapelle votive ouvrant sur la place (Cappella di Piazza)(fig. 16) ${ }^{70}$. Nous n'entrerons pas ici dans le détail de la mise en oeuvre, qui s'est prolongée avec des hiatus au cours de nombreuses décennies et a impliqué plusieurs artistes. Quant au programme, il a été centré sur la personne du Christ avec, en 1392, une peinture surmontant l'autel; Marie s'y est vue associée, du moins en $1426^{71}$. Les piles d'angles, creusées de niches, devaient recevoir autour de 1400 des statues d'apôtres, qui n'ont finalement pas toutes été réalisées; le parti de disposer ces figures sur les éléments porteurs n'innovait évidemment guère, par rapport à ce qui était d'usage depuis plus d'un siècle ${ }^{72}$; mais on peut sans doute considérer comme relevant de notre propos le fait que Barthélemy ${ }^{73}$, longtemps vénéré comme l'un des patrons de la ville ${ }^{74}$, se trouve en position relativement privilégiée: soit de pleine face, et dans une des niches du niveau inférieur, presque à portée de main des fidèles.

Peu après, le remodelage de la fontaine de l'autre côté du Campo (fig. 17) a foumi l'occasion d'exprimer bien plus fortement encore l'imbrication de la ville et des puissances supérieures. Après certains amendements, le programme réalisé de 1414 à 1419 par Jacopo della Quercia pour cette Fonte Gaia développe une iconographie complexe (fig. 18) ${ }^{75}$. L'ensemble y est centré sur la Vierge, accostée de deux anges et des personnifications des quatre vertus cardinales, des trois vertus théologales et de la sagesse, à la paroi du fond et au départ des ailes. La Création de l'homme et l'Expulsion de l'Eden se font face aux extrémités des ailes, que surmontent deux groupes en ronde-bosse: plutôt que des allégories de la Charité et de la Libéralité, on y reconnaîtra Rhea Silvia et Acca Larentia, mère et nourrice de Romulus et de Rémus ${ }^{76}$; les louves qui, en partie basse, complètent le tout renvoient en effet sans équivoque à des origines mythiques en relation avec celles de l'Urbs; et l'on a d'autre part déjà pu relever, dans le décor de plusieurs salles du palais, toute l'importance des références romaines ${ }^{77}$. Le message global de cette Fonte Gaia s'avère ainsi de portée considérable. La Divine Protectrice de la cité, face à son palais, se présente bien entendu encore comme l'inspiratrice du bon gouvernement: les Vertus qui l'entourent le traduisent parfaitement, en faisant écho à celles qu'Ambrogio Lorenzetti avait associées à la personnification de ce même gouvernement dans la Salle des Neuf ${ }^{78}$. Cela se trouve en outre replacé, ici, dans 
une vaste pespective historique: celle du prestigieux modèle romain sans doute; mais surtout celle d'un élargissement jusqu'aux origines de l'humanité, en mettant bien l'accent sur la funeste conséquence du péché initial. Le discours acquiert alors une véritable dimension sotériologique: car on suggère ainsi que la perversion de l'homme s'abolit par l'exercice d'un pouvoir d'émanation céleste dans le cadre même de la cité.

En guise de conclusion à ce panorama, deux séries de remarques nous semblent devoir être formulées. La première est relative aux figures mêmes impliquées dans ces programmes. La Vierge y assume sans conteste un rôle dominant, et l'on ne saurait certes s'en étonner à une époque où l'Occident chrétien tout entier privilégie la dévotion mariale; mais - et le cas siennois s'avère à cet égard exemplaire - on s'efforce à présent d'introduire dans ce culte une donnée spécifique à la cité, afin que s'établisse entre celle-ci et Marie un lien de caractère personnel. Au départ du processus, la victoire de Montaperti a joué ici un rôle décisif; et c'est ensuite par le biais d'associations précises, systématiquement opérées, que s'est manifestée cette indéfectible attache. La proximité des saints patrons traduit donc celle de la ville même, à toutes les étapes de la vie de Marie comme dans la révélation intemporelle de sa gloire. Et pour renforcer cette captation, on ne manque pas d'effectuer les "actualisations" nécessaires; confirmant à cet égard les observations fondées sur les sources écrites ${ }^{79}$, nos programmes mettent dès que possible au premier plan des saints ou des bienheureux fraîchement promus et pleinement immergés dans l'histoire locale: ainsi, auXVè s., Catherine et Bernardin interviennent-ils de plus en plus fréquemment, assez souvent suivis par des personnages comme Andrea Gallerani, Ambrogio Sansedoni ou plusieurs autres de moindre relief mais en cela même, précisément, plus représentatifs presque de la tendance en question. On notera cependant que - dans un souci d'efficacité cumulative sans doute - le souvenir des anciens protecteurs ne s'estompe pas pour autant: l'apôtre Barthélemy est toujours en bonne place à la Cappella di Piazza; et l'on fera encore peindre par Sodoma dans la salle du Conseil du palais, en 1529, un Saint Ansanus et un Saint Victor... ${ }^{80}$

Un retour aux lieux de déploiement de cette iconographie constituera le second volet de nos réflexions finales. Quant à la cathédrale, sa dépendance institutionnelle de la personne de l'êvêque ne la prédisposait pas particulièrement à ces in- fléchissements civiques. Ceux-ci devenaient inéluctables, cependant, dans la mesure où la Commune intervenait très directement dans les nouveaux aménagements; on le constate aussi bien pour la discussion et le financement des entreprises architecturales que pour la mise en oeuvre des programmes figurés: il suffit de rappeler ici, dans deux regisires disincts, le rôle omniprésent du Consiglio della Campana ${ }^{31}$, ou les injonctions ponctuelles pressantes aux gestionnaires de l'Oeuvre de la cathédrale pendant la réalisation du nouveau grand retable par Duccio ${ }^{82}$. En ce qui concerne le palais, dévolu tout aussi institutionnellement au pouvoir laïc, on doit d'une part souligner que l'introduction de sujets sacrés y a été opérée presque aussitôt, et dans les salles de délibération tout autant que dans les chapelles. Et cette thématique religieuse est demeurée par la suite très largement majoritaire: seules en effet, pour la période ici embrassée, la Salle des Neuf et la Sala Nova (plus tard dite Sala di Balia) présentent des ensembles importants d'esprit plus exclusivement allégorique ou historique ${ }^{83}$; encore l'inclusion même dans un édifice marqué du sceau de la Vierge incite-t-elle à ne pas considérer ces peintures de façon trop indépendante. On a pu voir, en outre, que les offices institués pour les opérations les plus matérielles - administration financière, services d'approvisionnement ou de perception de l'impôt - n'étaient pas moins investis par ce qui procédait de la sphère céleste. L'espace "ouvert" de la ville, enfin, ne pouvait échapper à l'affirmation du même courant, puisque la conscience de l'ordre nouveau devait s'imposer au citoyen jusque dans les actes ordinaires de la vie quotidienne. Plus que la Cappella di Piazza, réalisation liée au souvenir ponctuel de l'épidémie de 1348, la fontaine monumentale du Campo reflète l'établissement permanent de cette emprise. On ne saurait en effet trop souligner l'importance vitale de ce point d'alimentation en eau, en plein centre d'une ville de collines où les autres fontaines se trouvaient en partie basse à la périphérie $^{84}$. Et c'est sans doute dans le programme de la Fonte Gaia que s'exprime avec le plus d'ampleur, comme on l'a vu, l'idéologie de ce temps: suggérant désormais sa pleine osmose avec Marie, le gouvernement civil n'hésite plus à se présenter comme jalon essentiel dans l'économie du salut; ainsi se parachève l'exaltation de cette "religion civique" dont l'image, par l'immédiateté de son impact et sa capacité de synthèse, s'avérait bien la plus apte à proclamer l'esprit.

\footnotetext{
' G. LOBRICHON, La religion des laïcs en Occident. XIè-XVè siècles, Paris, 1994, p. 135-140.

${ }^{2}$ La religion civique à l'époque médiévale et moderne (Chrétienté et Islam). Colloque organisé par le Centre de recherche "Histoire sociale et culturelle de l'Occident. XIIè-XVII siècles" de l'Université Paris X-Nanterre et l'Institut Universitaire de France. Université de Paris X-Nanterre, 21 -23 juin 1993 (actes actueliement sous presse). Pour le cas de Sienne, dont il sera précisément question ici, voir déjà l'article d'A. Vauchez, la commune de Sienne, les ordres mendiants et le culte des saints. Histoire et enseignements d'une crise (nov. 1328 - avr. 1329), dans Mélanges de l'Ecole française de Rome (Moyen âge), 89/2, 1977, p. 757-767.

${ }^{3}$ H. VAN OS, Sienese Altarpieces. 1215-1460, I, Groningen, 1984 (et réimpression 1988), p. 11-17 et fig. 9. Partie centrale de ce retable aujourd'hui conservée dans la cathédrale (Cappella del Voto).

${ }^{4}$ On peut notamment renvoyer au format et à l'articulation de ceux conservés à la Pinacothèque nationale de Sienne (également attribués au cercle de Guido de Siena), au Musée national S. Matteo de Pise (signé de Deodato Orlandi, en 1301), et dans une collection privée à Colle di Val d'Elsa (d'un anonyme siennois de la seconde moitié du XIHè s.): cf. H. VAN OS, ibid., p. $18-19$ et fig. 11-13; également P. TORRITI, La Pinacoteca nazionale di Siena I dipinti dal XII al XV secolo, Gênes, 1980, nos. 7 et 6, p. 26-27 et 32-33. Cf. aussi, avec alors un Christ au centre et à ses côtés Marie, des saints d'importance comparable et le dédicataire de l'église, E. CARLI, Il Museo di Pisa, Pise, 1974, no. 30, p. 40 et fig. 45.

${ }^{5}$ H. BELTING, Bild und Kult. Eine Geschichte des Bildes vor dem Zeitalter der Kunst, 2ème éd., Munich, 1991 (et réimpression 1993 ), p. 447.

${ }^{6}$ K. VAN DER PLOEG dans H. VAN OS, op. cit., I, p. 131-132 et n. 86, p. 152 (avec la restitution de trois autels distincts dans cette crypte: celui de Crescentius; celui de Barthélemy, Fabien et Sébastien; et celui de Savinus et Ansanus - puis Victor à la fin du XIIIè s.).

${ }^{7}$ H. VAN OS, op. cit., I, p. 12 et fig. 1; ibid., p. 12-15 et fig. 2, 3, 8 pour des panneaux de même format avec figure centrale trônante et scènes narratives de chaque côté. Si l'on envisage pour le retable postérieur à 1260 des figures latérales en buste, cependant, on pourrait aussi songer à certains des grands saints que l'on retrouvera en pied aux côtés de la Vierge de Duccio en 1308-11.

${ }^{8}$ G. RAGIONIERI, Duccio. Catalogo completo dei dipinti, Florence, 1989, p. 9 et no. 6, p. 35-37; il est évidemment hors de notre propos de revenir sur les doutes émis par certains auteurs (Cimabue plutôt que Duccio ?) quant à l'attribution de l'oeuvre.
} 
${ }^{9}$ H. VAN OS, op. cit., I, p. 39-63 (avec reconstitution de l'avers et du revers dans l'ćtat d'origine, d'après J. White, fig. 41-42); G. RAGIONIERI, op. cit., p. 11-16 et nos. 1.-41, p. 46-135. Pour la connotation civique de l'oeuvre, cf. aussi H.P. RIEDL, Das Maestà-Bild in der Sieneser Malerei des Trecento, unter besonderer Berücksichtigung der Darstellung im Palazzo Communale von San Gimignano, Tübingen, 1991, p. 15-31 (dont nottament 29-31). ${ }^{10} \mathrm{La}$ suite - Sis Duccio vita te quia pinxit ita - attire nommément l'attention sur l'artiste, mais s'accorde sinon absolument avec l'esprit de la prière précédente; et elle suppose aussi une transmission par le même truchement des quatre patrons.

${ }^{"}$ Cf. Giovanni d'Agostino e il "Duomo nuovo" di Siena (ouvrage collectif, éd. par le Rotary Club Siena Est), Gênes, 1987, en particulier p. $22-23$ (E. Carli).

${ }^{12}$ La Porta del Perdono, au flanc sud de l'ancienne cathédrale, se justifiait par la même raison; cf. K. VAN DER PLOEG dans H. VAN OS, op. cit., I, p. 138.

${ }^{1: 3}$ Rappelons qu'il s'agissait de réduire l'édifice existant au transept d'une nouvelle cathédrale avec chevet au Nord: projet mûri entre 1316 (plan prévoyant un simple agrandissement du choeur) et 1339 (début des travaux du Duomo nuovo); cf. K. VAN DER PLOEG dans H. VAN OS, op. cit., I, p. 141-143.

${ }^{14}$ K. VAN DER PLOEG dans H. VAN OS, op. cit., I, p. 143-144 et diag. 16; pour cette même disposition, encore attestée en 1420, cf. G. ARONOW, ibid., II, p. 226.

${ }^{15} \mathrm{H}$. VAN OS, op. cil., I, p. 76-89, avec renvoi aux sources en question.

${ }^{16}$ H. VAN OS, op. cit., II, p. 113-114 et fig. 111 (d'après H. Bason, E. Muller et B. Steinhoff).

${ }^{17}$ Annonciation, Nativité de Jésus et Purification (en rapport avec la Présentation au Temple), du moins; cf. H.W. VAN OS, Marias Demut und Verherrlichung in der sienesischen Malerei 1300-1450, La Haye, 1969, p. 3, n. 2.

${ }^{18}$ E.C. SOUTHARD, The Frescoes in Siena's Palazzo Pubblico 1289-1539. Studies in Imagery and Relations to other Communal Palaces in Tuscany, Ph. D. Indiana University, 1978, fac-simile Ann Arbor (Michigan), 1982; G. BORGHINI, La decorazione, dans C. BRANDI dir., Palazzo pubblico di Siena. Vicende costruttiue e decorazione, Milan, 1983, p. 147-349. Pour la salle "de la Mappemonde", qui sera ci-après envisagée en premier lieu, voir également D. NORMAN, "The glorious deeds of the Commune": civic patronage in art, dans D. Norman éd., Siena, Florence and Padua. Art, Society and Religion, 1280-1400, I, Interpretative Essays, New Haven-Londres, 1995, p. 133-140.

19 E.C. SOUTHARD, op. cit., p. 430-432.

${ }^{20}$ G. BORGHINI, op. cit., p. 215 (et liste p. 266); pour la valeur documentaire et les implications historiques de ces scènes (en particulier quant à l'expansion communale aux dépens de droits féodaux fondés sur des privilèges impériaux), ct. M. SEIDEL, "Castrum pingatur in Palatio", 1. Ricerche storiche e iconografiche sui castelli dipinti nel palazzo Pubblico di Siena, dans Prospettiva, XXVIII, 1982, p. 17-41.

${ }^{21}$ E.C. SOUTHARD, op. cit., p. 216-228; G. BORGIINI, op. cit., p. 266-268 et fig. 329-336; P. LEONE DE CASTRIS, Simone Martini. Catalogue complet, éd. franç., Paris, 1991, p. 7, 9-11, ainsi que nos. 3 et 8, p. 24-27 et 61-63.; H. P. RIEDL, op. cit., p. $32-50$ (dont notamment 48-50).

${ }^{22}$ Diligite iustitiam qui iudicatis terram.

${ }^{23}$ Li angelichi fiorecti, rose (e) gigli,/ onde s'adorna lo celeste prato, / no(n) mi dilettan più ch'e buon consigli,/ (m)a (talor) (veggi)o chi (per) proprio stato/ disprezza me (e) la mia ter(r)a ingan(n)a:l e quando parla peggio è pi lodato:/ con guardi ciaschedun cui questo dir condanna.

Responsio Virginis ad dicta sanctorum:/ diletti m(i)ei, ponete nelle mentil che li devoti vostri preghi onesti/ come vorrete voi faro co(n)tenti,/ ma se $i$ potenti a debili fien molesti,/gravando loro o con vergogne o danni,/le vostre orason non son per questi/ ne per qualunque la mia terra inganni.

${ }^{24}$ E.C. SOUTHARD, op. cit., p. 224.

${ }^{25} \mathrm{Cf}$. déjà l'Annonciation de la cathédrale, ici même, fig. 9; pour d'autres attestations, cf. notamment P. Leone de Castris, no. 1, p. 20-21; no. 2, p. 22-23; no. 6, p. 50-54; no. 7, p. 55-60; no. 11, p. 71-73; no. 12, p. 74-75; no. 14, p. 78-79; no. 18, p. 86-87; no. 30, p. 90-92; no. 21, p. 93-96; no. 26, p. 113121; no. 31, p. 130-131; no. 32, p. 132-133.

26) Peinture découverte en 1981, et attribuée tour à tour à Duccio, Pietro Lorenzetti, Memmo di Filipuccio et Simone Martini: cf. G. BORGHINI, op. cit., p. 215, 218-219 et fig. 241; pour le résumé de la discussion sur le peintre - et l'identification du bourg -, cf. P. LEONE DE CASTRIS, no. 3A, p. 138140.

${ }^{27}$ E.C. SOUTHARD, op. cit., p. 229-235; G. BORGHINI, op. cit., p. 219-220 et fig. 240; pour le résumé de la discussion sur la date de cette oeuvre et son attribution - au demeurant toujours la plus vraisemblable - à Simone Martini, cf. P. LEONE DE CASTRIS, op. cit., no. 24, p. $104-108$.

${ }^{28}$ E.C. SOUTHARD, op. cit., p. 241-248; G. BORGHINI, op. cit., p. 224, 226 et fig. 266-268 (peinture de Lippo Vanni).

${ }^{24}$ E.C. SOUTHARD, op. cit., p. 252-257; G. BORGHINI, op. cit., p. 256, 265 et fig. 313 (peinture de Giovanni di Cristoforo Ghini et Francesco d'Andrea). On rappellera en outre la représentation, dans cette même salle, en 1424, de la conquête de nouveaux territoires (aujourd'hui disparue): G. BORGHINI, op. cit., p. 256.

"3i E.C. SOUTHARD, op. cit., p. 236-237; G. BORGHIN1, op. cit., p. 223.

${ }^{31}$ E.C. SOUTHARD, op. cit., p. 266-267; E. CARLI, Gli scultori senesi, Milan, 1980, 35-36; M. CORDARO, dans C. BRANDI dir., Palazzo pubblico di Siena. Vicende costruttive e decorazione, Milan, 1983, p. 87; G. BORGHINI, ibid., p. 266-268 et fig. 110-111.

${ }^{32}$ D'autres panneaux de ce siège, aujourd'hui disparus, représentaient des héros de la Rome républicaine (cf. G. MILANESI, Documenti per la storia dell'arte senese, II, Sienne, 1854, p. 240-241); on retrouvera des références historiques de ce genre dans le vestibule de la chapelle du premier étage, notamment (cf. ci-après, anticappella).

${ }_{33}$ E.C. SOUTHARD, op. cit.., p. 249-252; G. BORGHINI, op. cit., p. 270 et fig. 343-344.

${ }^{34}$ A. VAUCHEZ, La sainteté en Occident aux derniers siècles du Moyen âge, 2ème éd. revue, Rome, 1988, notamment p. 7, 89 n. 44, 448 (Bernardin) et 427, 440-442, 487, 527, 613 (Catherine).

${ }^{35} \mathrm{G}$. BORGHINI, op. cit., p. 147.

${ }^{3 i}$ E.C. SOUTHARD, op. cit., p. 165; G. BORGHINI, op. cit., p. 162.

${ }^{37}$ Cancelleria di Biccherna, d'après Pecci (milieu du XVIIIè s.); aujourd'hui Sala della Giunta, au rez-de-chaussée, dans l'axe médian du palais, avec une fenêtre sur la place du marché.

${ }^{38}$ E.C. SOUTHARD, op. cit., p. 165-171; G. BORGHINI, op. cit., p. 162-163 et fig. 164, 178-180. Témoigne toujours de cette composition antérieure l'inscription avec la signature de Lippo Vanni sur le chancel en trompe-l'oeil; quant à la composition de Sano di Pietro, Domenico di Bartolo y a manifestement collaboré pour plusieurs figures.

3.. .. Vergine madre dell'eterno Dio dalle cui sante mani se coronata, sieti raccomandata la tua diritta e fedel cit(t)à di Siena ...

${ }^{40}$ E.C. SOUTHARD, op. cit., p. 171-173 et 176-178; G. BORGHINI, op. cit., p. 162-163 et lig. 164, 181-182. La Sainte Catherine a naturellement été l'objet de profondes retouches à époque postérieure. 
${ }^{41}$ E.C. SOUTHARD, op. cit., p. 173-176; G. BORGHINI, op. cit., p. 167 et fig. 189.

${ }^{42}$ Cf. notamment M.A. CEPPARI, P. SINIBALDI, C. ZARRILLI, dans Le Biccherne (ouvrage collectif), Rome, 1984, p. 144 n. 2 (avec renvoi à des études antérieures sur cette période de l'histoire locale).

${ }^{43}$ A. VAUCHEZ, op. cit., notamment p. 155 n. 16, 236 n. 152, 285.

${ }^{44}$ Cf. Le Biccherne (cit. ci-dessus, n.43), notamment p. 1-10 (U. Morandi).

${ }^{45}$ M.A. CEPPARI, P. SINIBALDI, C. ZARRILLI, ibid., respectivement no. 58, p. 156-157 (par Sano di Pietro); no. 59, p. 158-159 (d'auteur anonyme; le camerlingue en charge appartenant lui-même à l'ordre des servites); no. 65, p. 170-171 (par Francesco di Giorgio Martini). Voir aussi, ibid., no. 37, p. 114-115 (Sainte Trinité avec quatre saints, de 1367; attribuée hypothétiquement à Niccolo di Buonaccorso); no. 47, p. $134-135$ (Saint Antoine abbé accosté de deux dominicains, de 1414, d'auteur anonyme; la présence des dominicains s'expliquant par l'appartenance du camerlingue en charge à cet ordre); no. 50, p. 140-141 (Saint Jérôme, de 1436, par Giovanni di Paolo); no. 61, p. 162-163 (colombe de paix accostée de deux autres bienheureux servites, de 1457, par Sano di Pietro; le camerlingue en charge étant de nouveau un servite); no. 63, p. 166-167 (couronnement du pape Pie II sous le buste de la Vierge et surmontant une représentation de la ville, de 1460, par Vecchietta).

${ }^{46}$ W. M. BOWSKY, A Medieval Italian Commune. Siena under the Nine, 1287-1355, Berkeley-Los Angeles-Londres, 1981, notamment p. $185-186$.

${ }^{47}$ Peintures aujourd'hui disparues; cf. E.C. SOUTHARD, op. cit., p. 200-203; G. BORGHINI, op. cit., p. 191, avec rejet de l'hypothèse d'E.C. Southard quant à une reprise de la composition de Nicola d'Ulisse dans une Vierge couvrant de son manteau saint Bernardin et sainte Catherine ( $i b i d$., fig. 229). ${ }^{48}$ Respectivement, cf. M.A. CEPPARI, P. SINIBALDI, C. ZARRILLI, op. cit., no. 71, p. 182-183 (par Neroccio di Bartolommeo de' Landi); no. 72, p. 184-185 (d'auteur anonyme); no. 75, p. 190-191 (par Guidoriccio Cozzarelli); no. 77, p. 194-195 (à nouveau par Guidoriccio Cozzarelli). Voir également ibid., no. 25, p. 387 (Vierge de Miséricorde, d'auteur anonyme, 1388; aujourd'hui disparue); no. 24, p. 88-89 (Nativité, d'auteur anonyme, 1334); no. 21, p. 387 (Annonciation, d'auteur anonyme, 1339, aujourd'hui disparue); no. 34, p. 108-109 (Présentation au Temple, par Lucca di 'Tommè, 1357); no. 37, p. 388 (Vierge à l'Enfant entre deux saints, d'auteur anonyme, 1431, aujourd'hui disparue); no. 52, p. 144-145 (Saint Pierre d'Alexandrie accosté de deux anges, par Giovanni di Paolo, 1440); no. 54, p. 148-149 (Flagellation, par le Maître de l'Observance, 1441); no. 55, p. 150-151 (saint Michel et le dragon, à nouveau par le Maître de l'Observance, 1444); no. 56, p. 152-153 (Annonciation, par Giovanni di Paolo, 1445); no. 40, p. 388 (saint Augustin, d'auteur anonyme, 1449, aujourd'hui disparu); no. 60, p. 160-161 (Annonciation entre saint Bernard et le pape Calixte III, protecteur de Sienne, d'auteur anonyme, 1456); no. 67, p. 174-175 (allégorie de la Sagesse émanant de Dieu, par Sano di Pietro, 1471); no. 73, p. 186-187 (Présentation au Temple entre les saints Jean l'Evangéliste et Nicolas de Bari, par Guidoriccio Cozzarelli, 1484); no. 74, p. 188-189 (Sacrifice d'Isaac, par Bernardino Fungai, 1485); no. 80, p. 200-201 (réception des stigmates par sainte Catherine, d'auteur anonyme; 1498 ou 1499).

${ }^{49}$ E.C. SOUTHARD, op. cit., p. 202-203; P. TORRITI, op. cit., no. 18, p. 124-125; G. BORGHINI, op. cit., p. 210, 268; M.A. CEPPARI, P. SINIBALDI, C. ZARRILLI, op. cit., no. 29, p. $98-99$.

${ }^{50}$ Residenza del Magistrato del Sale o della grascia, Stanza del Biado. On y accédait directement depuis la place du Campo.

${ }^{51}$ E.C. SOUTHARD, op. cit., p. 179-189; G. BORGHINI, op. cit., p. 181, 193 et fig. 232.

52 Suivant G. BORGHINI, ibid.; E.C. SOUTHARD songeait pour sa part à une allégorie de la Foi, originellement accompagnée des deux autres vertus théologales (dans la partie aujourd'hui lacunaire).

${ }^{53}$ Cf. la liste donnée par E.C. SOUTHARD, op. cit., p. 184-186.

${ }_{54}^{5}$ E.C. SOUTHIARD, op. cit., p. 189-190; P. TORRITI, op. cit., no. 241, p. 274-275; G. BORGHINI, op. cit., p. 193 et fig. 233.

${ }^{55}$ E.C. SOUTHARD, op. cit., p. 197-199, avec localisation de la pièce en question dans l'aile droite et vers l'arrière du palais, et identification de la peinture de Francesco Migliori avec une Sainte Catherine conservée dans l'actuel office du Personnel (auparavant Ufficio della Comunità). G. Borghini, op. cit., p. 163, repousse à la fois cette localisation de la pièce et l'identification de la peinture; cette dernière (reproduite fig. 183) aurait autrefois présenté la signature de Sano di Pietro, mais a été fortement retouchée.

${ }^{56}$ E.C. SOUTHARD et G. BORGHINI, ibid.

${ }^{57}$ C. BRANDI, Palazzo pubblico di Siena. Vicende costruttive e decorazione, Milan, 1983, p. 25.

${ }^{58}$ E.C. SOUTHARD, op. cit., p. 314-316 et 424; G. BORGHINI, op. cit., p. 223, 323 et fig. 261. Le globe comportait originellement, en son centre, le lion emblématique du gouvernement du peuple. Par ailleurs, la peinture a été déplacée et se trouve aujourd'hui au premier étage du palais (à l'entrée).

5." (Ma)ndatum novam do vobis ut diligati(s) i(n) vice(m).

${ }^{60}$ E.C. SOUTHARD, op. cit., p. 282; G. BORGHINI, op. cit., p. 220 et fig. 244-245.

${ }^{61}$ En usage jusqu'en 1404/05. Cf. E.C. SOUTHARD, op. cit., p. 143-162; G. BORGHINI, op. cit., p. 193, 198, 210 et fig. $234-239$.

${ }^{62}$ Retouché par Segna di Bonaventura en 1321.

${ }^{63}$ Cette Crucifixion avait dû remplacer une croix peinte de modestes dimensions, attestée dès 1306: cf. E.C. SOUTHARD, op. cit,, p. $157-158$.

${ }^{64}$ E.C. SOUTHARD, op. cit., p. 143; M. CORDARO dans C. BRANDI dir., Palazzo pubblico di Siena. Vicende costruttive e decorazione, Milan, 1983, p. 83.

${ }^{65}$ E.C. SOUTHARD, op. cit., p. 321-353; G. BORGHINI, op. cit., p. 268-270 (avec discussion de l'attribution à Simone Martini du retable d'autel installé dans cette chapelle - et de toute manière à un autre emplacement auparavant - en 1404/06) et fig. 337-338.

${ }^{66}$ Par le même Taddeo di Bartolo; également disparu depuis 1686.

${ }^{67}$ E.C. SOUTHARD, op. cit., p. 345-346; M. CORDARO, op. cit., p. 83 et fig. 102.

${ }^{6}$ E.C. SOUTHARD, op. cit., p. 354-371; G. BORGHINI, op. cit., p. 241, 251, 256 et fig. 299-312,341.

${ }^{69}$ D. HANSEN, Antike Helden als "causae". Ein gemaltes Programm im Palazzo Pubblico von Siena, dans H. BELTING et D. BLUME dir., Malerei und Stadtkultur in der Dantezeit, Munich, 1989, p. 133-148.

${ }^{70}$ M. CORDARO, op. cit., p. 57, 82 et fig. 76-96.

${ }^{71}$ E.C. SOUTHARD, op. cit., p. 129; Christ dû à Cristoforo di Bindoccio et Meo di Pietro, et tenda a la Madona payée à Ludovico di Luche; ces oeuvres ont aujourd'hui disparu.

${ }^{72}$ Cf. naturellement le prototype fourni par les apôtres adossés au supports de la salle haute de la Sainte-Chapelle du Palais à Paris (1243-48).

${ }^{73}$ Oeuvre de Lando di Stefano; outre M. Cordaro, loc. cit. supra (n. 71), cl. E. CARLI, Gli scultori senesi, Milan, 1980, p. 26.

${ }^{74} \mathrm{Cf}$. ci-avant, au vitrail du chevet de la cathédrale, fig. 1.

${ }^{75} \mathrm{Cf}$. notamment D. CINELLI, notice XIII dans Jacopo della Quercia nell'arte del suo tempo (catalogue de l'exposition de Sienne puis Grosseto), Florence, 1975, p. 106-109 et photographies p. 109-119; E. CARLI, op. cit., p. 28-30 et fig. 167-171; M. CORDARO, op. cit., p. 87-88 et fig. 115-130; J.H. BECK, Jacopo della Quercia, New York, 1991, p. 81-94, 148-150, et fig. 20-21, 48-73.

${ }^{76}$ L'identification des deux allégories a été préférée notamment par F. BISOGNI, Sulliconografia della Fonte Gaia, dans Jacopo della Quercia fra Gotico 
e Rinascimento (ouvrage collectif), Florence, 1977, p. 109-114 (d'oû J.H. BECK, loc. cit., sans nouvelle argumentation); pour l'identification de Rhea Silvia et d'Acca Larentia, cf. M. CORDARO, op. cit., p. 88 (qui signale que cette opinion est également partagée par C. BRANDI).

${ }^{7}$ Cf. ci-avant, sur le siège marqueté placé sous la grande Maestà dans la salle du Conseil (n. 33), et les héros de la Rome républicaine aux murs de l'anticappella; on n'oubliera pas non plus les peintures - disparues - de Simone Martini (figure de Marcus Attilius Regulus au premier étage, dans la Sala del Concistoro) et d'Ambrogio Lorenzetti (sujets de l'histoire romaine, à nouveau) au rez-de-chaussée et à l'extérieur - ? - du palais: cf. E.C. SOUTHARD, op. cit., respectivement p. 396-398 et 116-118, puis G. BORGHINI, op. cit., p. 220.

${ }^{78}$ E.C. SOUTHARD, op. cit., p. 282; G. BORGHINI, op. cit., p. 220 et fig. 244-245.

${ }^{79}$ A. VAUCHEZ, La sainteté en Occident aux derniers siècles du Moyen âge, 2ème éd. revue, Rome, 1988, p. 154-155.

${ }^{80}$ E.C. SOUTHARD, op. cit., p. 257-261; G. BORGHINI, op. cit., p. 270 et fig. 240, 346-347.

${ }^{81}$ Cf. notamment E. CARLI, Il Duomo di Siena e il Museo dell'Opera, Florence, 1976, p. 4, 10; pour l'institution de ce Consiglio della Campana comme conseil général de la Commune de Sienne, W.M. BOWSKY, A Medieval Italian Commune. Siena under the Nine, 1287-1355, Berkeley-Los AngelesLondres, 1981, p. 24.

${ }^{82}$ H. VAN OS, Sienese Altarpieces. 1215-1460, I, Groningen, 1984 (et réimpr. 1988), p. 42, avec renvoi, pour un point de vue plus général sur le patronage communal dans les églises, à J. LARNER, Culture and Society in Italy. 1290-1420, Londres, 1971, p. 65-86.

${ }_{83}$ E.C. SOUTHARD, op. cit., p. 271-296 et 372-393; G. BORGHINI, op. cit., p. 220-223, 226, 228 et fig. 242-260, 269-290. I1 s'agit respectivement des allégories et des effets du bon et du mauvais gouvernement par Ambrogio Lorenzetti (salle des Neuf), et de l'histoire du pape Alexandre III par Spinello Aretino (Sala di Balia). On ne placera naturellement pas sur le même pied que ces ensembles les scènes de bataille ou de cession de forteresse de la salle du Conseil, évoquées ci-avant: nous avons vu, en effet, qu'elles devaient être directement liées à la Maestà de Simone Martini; il en va de même pour les peintures de l'anticappella, que nous avons proposé de "lire" en étroite relation avec celles de la chapelle voisine.

${ }^{84}$ W.M. BOWSKY, op. cit., p. 14, avec renvoi à l'étude toujours fondamentale, sur ce point, de F. BARGAGLI-PETRUCCI, Le fonti di Siena e $i$ loro acquedotti, Sienne, 1906.

\title{
RELIGIJSK A IKONOGRAFIJA I GRADANSKA SVIJEST U POSLJEDNJIM STOLJEĆIMA SREDNJEGA VIJEKA: PRIMJER SIENE
}

\author{
SAŽETAK
}

Novija istraživanja nekolicine povjesničara ukazala su na pojavu "građanske religije" u smislu najvišeg izraza pobožnosti laika u posljednjim stoljećima srednjeg vijeka: tako se iskazuje dvostruka želja za afirmacijom komunalnog identiteta i ozakonjenja nove vlasti. Najvažnije mjesto u njezinu promicanju pripada figuralnim programima. Oslonit ćemo se u ovoj prilici na primjer Siene gdje već i sam broj ostvarenja koja su još uvijek in situ (ili su arhivski potvrđena), omogućuje najbolju prosudbu o opsegu pokreta, o komplementarnosti tema i njihovim postupnim mijenama.

Istraživanje može otpočeti u katedrali gdje, za razdoblje posljednjih desetljeća XIII. stoljeća i prvu polovicu XIV. stoljeća, vitraj svetišta, Ducciova slika na glavnom oltaru, četiri pomoćna oltara na križištu i južni portal kojim se ulazi u Duomo nuovo dovode do sukladnih opažanja: lokalni sveci zaštitnici prate Djevicu za života; oni joj se pridružuju — kao što se pridružuju i Kristu - i u izvanvremenskom očitovanju njezine slave.

I komunalna palača ima jednako indikativne programe. Valja pri tom razmotriti i one u dvoranama koje su služile vršenju raznih oblika vlasti. U njima Djevica predsjeda važnim događajima, štiti grad u vrijeme nedaća, a one koji gradom vladaju nadahnjuje u provedbi i najobičnijih dužnosti. Marijin lik se naravno slavi i u kapelama palače; predvorje kapele, uređene početkom XV. stoljeća, odlikuje doista historicizirajuća tematika - pozivanje na važne likove rimske Republike - no čini se da ga valja shvatiti pripremom za pristupanje nebeskim stvarnostima koje priziva susjedni sakralni prostor.

Konačno na Piazzi del Campo, još širi program razvija Fonte Gaia preoblikovana od 1414. do 1419.; cjelina što je tvore epizode Postanka, Djevica i povorka vrlina - za koje se uvijek smatra da nadahnjuju građansku vlast - sugerira odlučnu ulogu komunalne vlade u sprečavanju čovjekove propasti.

Zaključno se nameću dvije vrste primjedbi. Prije svega, u odnosu na korištene likove, ističe se stalno traženje uspostave veze osobnog karaktera između nebeskih sila - u prvom redu Djevice - i grada; sveci zaštitnici koje je grad odavno sebi odabrao, dobijaju svoju punu važnost; no, i u njihovoj se skupini provodi "aktualizacija" upadom onodobnih svetaca ili blaženih (Bernardina i Katarine, kao i nekih drugih, manje važnih).

Treba se vratiti ishodištima te ikonografije. Neizbježnom bi se pokazala nazočnost u katedrali jer je komunalno Vijeće u njoj izravno nadziralo uzastopna preuređenja. Jednako je važno da u komunalnoj palači, strogo laičkog obilježja, gotovo istodobno prevlađuju religijske teme. Afirmacija tog kretanja nije zaobišla ni "otvoreni" prostor grada; ondje je, na glavnom trgu na najsintetičkiji način završavala osmoza Marije, najveće mudrosti i vrline, središnjeg lika spasenja - i državne vlasti. 
